Journal of Educational

and Psychological Sciences

Volume (6), Issue (3): 30 Jan 2022

P: 57 - 81

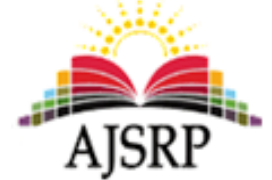

ISSN: 2522-3399

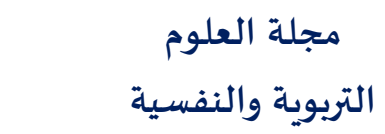

المجلد (6)، العدد (3): 30 يناير 2022 م

ص: 57 - 81

\title{
Accuracy of Estimate of the items and the ability parameters according to the two parameters Logistic model for TIMSS 2019 Test for the science subject for the second intermediate class in Kingdom of Saudi Arabia
}

\author{
Sarah Ouda Saleh Albalawi \\ Ministry of Education || KSA \\ Shaher Khaled Suleiman \\ College of Education and Arts || Tabuk university $\|$ KSA
}

\begin{abstract}
The study aimed to disclose the Accuracy of Estimate of the difficulty and distinction parameter for the item and the ability for TIMSS Test for the science subject for the second intermediate class in Kingdom of Saudi Arabia according to the two parameter Logistic model for the theory of item responding. To achieve the aim of the study, the researcher used the descriptive analysis approach. She has used the data of TIMSS 2019 Test for the science subject for a sample of 5680 male and female student. They were chosen randomly from 209 school in Kingdom of Saudi Arabia. The statistical programs SPSS and BILOG- MG3 were used to analyze the data. The results showed that: the values of the difficulty parameter ranges between $(1.79-)$ to $(4.04)$ with Arithmetic average $(0.42)$. it showed that the minimum value of the standard error in assessing the difficulty parameter which reached (0.098). the difficulty of the item value reached (-0.69), the value of the distinction parameter ranged between (0.38) to (1.50) with Arithmetic average (0.85). The minimum value of the standard error in assessing the distinction parameter which reached (0.09). the distinction of the item value reached (0.38). As for the values of assessing the ability for the individuals in the test, it ranged between (- 3.610) to (4) with Arithmetic average (0.03). The minimum value of the standard error reached (0.49) at assessing the ability (-0.58). the study concluded many recommendations, including: establishing the training courses and workshops for male and female teachers in building the tests items according to the levels of TIMSS test, engaging the teachers in the workshops which are established by the education ministry to discuss TIMSS results and making more researches concerning TIMSS test by using the other models for the respond theory for the item.
\end{abstract}

Keywords: Accuracy of Estimate, items parameters, ability, the two parameters Logistic model, TIMSS Test.

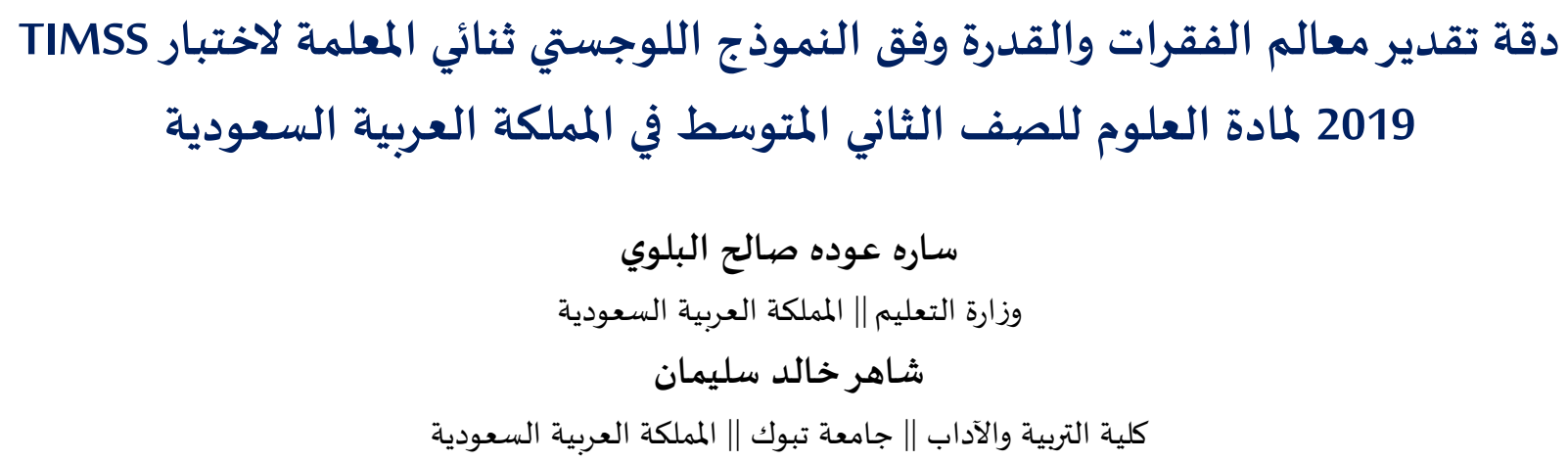


المستخلص: هدفت الدراسة إلى الكشف عن دقة تقدير معلمة الصعوبة والتمييز للفقرة والقدرة لاختبار TIMSS لمادة العلوم للصف

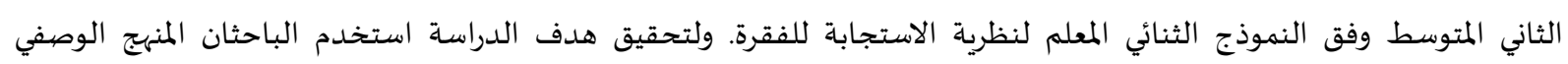

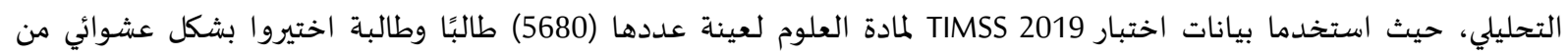
(209) مدرسة في المملكة العربية السعودية، وتم استخدام البرنامج الإحصائي SPSS وBILOG-MG3 لتحليل البيلية البيانات. وأظهرت النتائج:

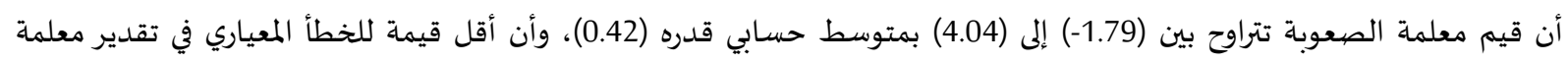

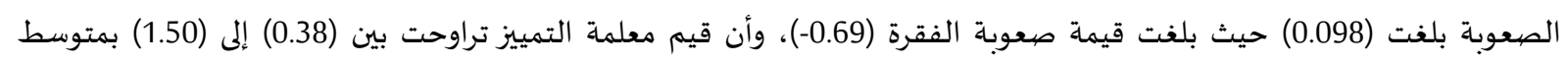
حسابي قدره (0.85)، وأقل قيمة للخطأ المعياري لتقدير معلمة التمييز بلغت (0.09) حيث بلفيثة بلفت قيمة تمييز الفقرة (0.38)، أما قيم تقدير

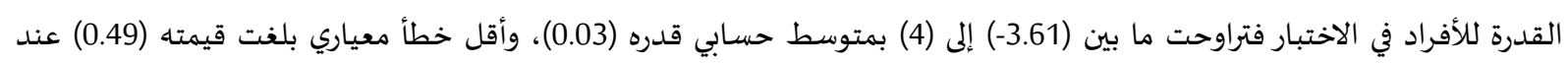

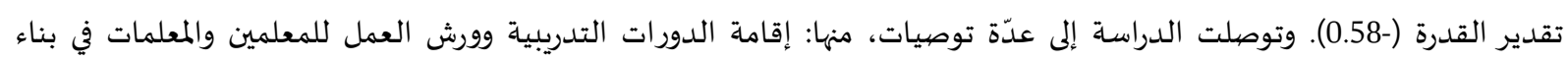

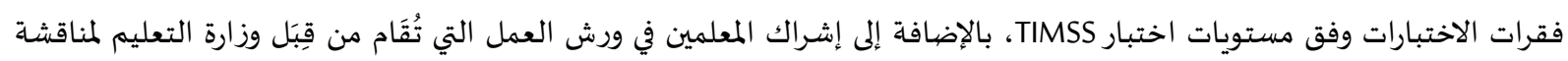

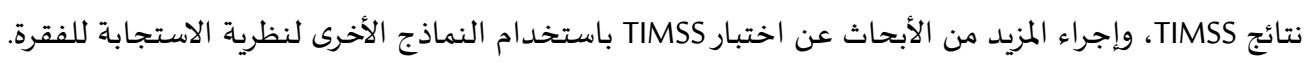
الكلمات المفتاحية: دقة تقدير، معالم الفقرات، القدرة، نظرية الاستجابة للفقرة، اختبار TIMSS.

المقدمة.

تسعى الأنظمة التعليمية باستمرار إلى تتبع عمليات التطوير والتحسين، لضمان جودة مخرجاتها المبنية على الى النهان

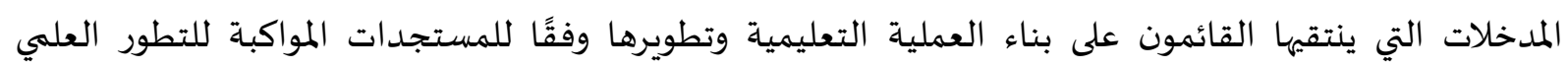

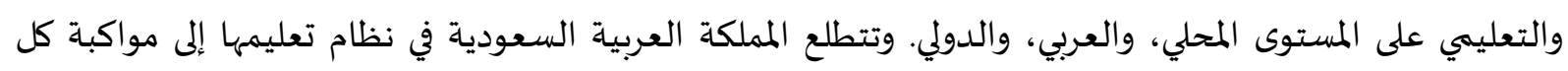

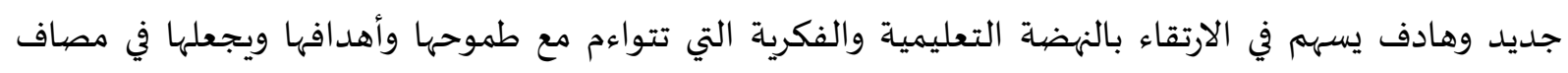

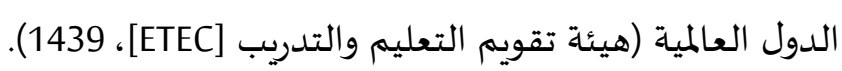

لذا شاركت المملكة العربية السعودية في الدراسات والاختبارات الدولية بأنواعها، واتجاهاتها، ومراحلها. العمرية، وفق دراسات متتالية ومتعددة، مما يدل على حرص قيادات التعليم لدينا على رفع كفاءة التعليم والوعي

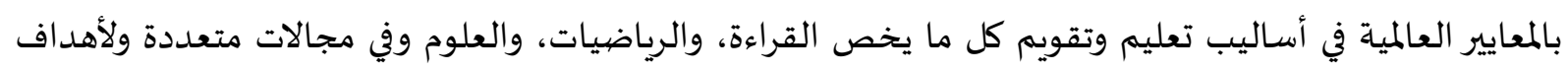
متنوعة (ETEC,1439).

هTIMSS» Trend in International هذا، وتعد دراسة التوجهات الدولية في الرياضيات والعلوم Mathematics and Science Study

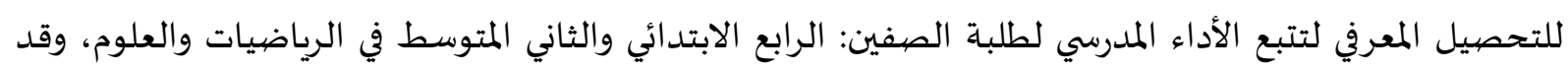

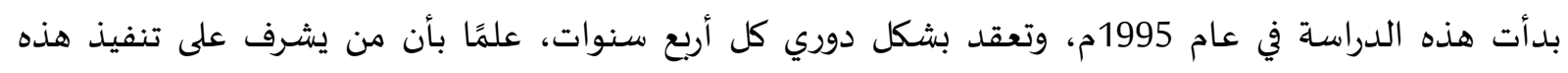

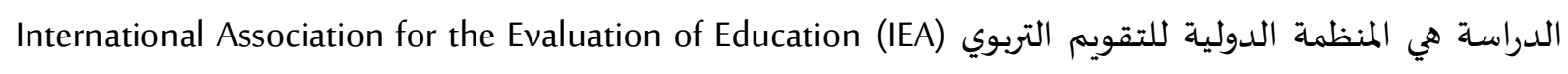

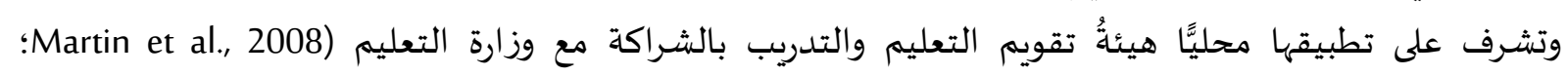
(ETEC,1439

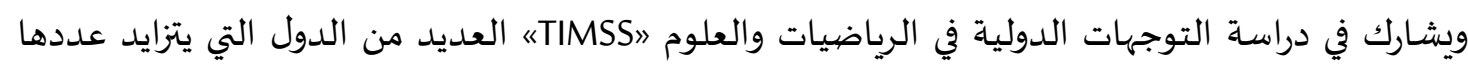

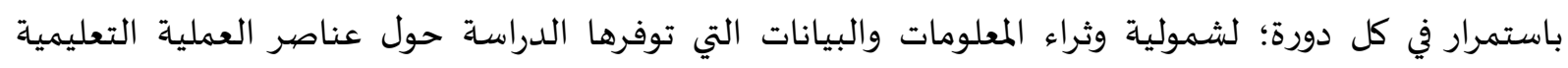

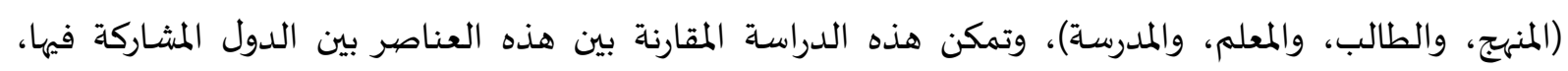

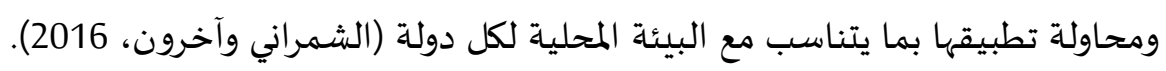

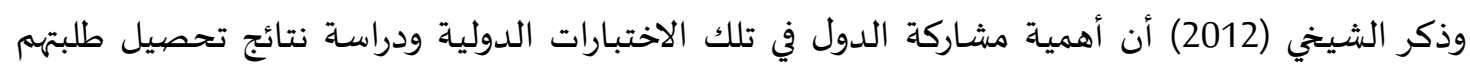
فيها؛ تبرز في تحديد أوجاه القوة والقصور لديهم، ومن ثم الاستفادة من تلك النتائج في إعداد الخطط 
والاستراتيجيات اللازمة لتحسين وتطوير مستوى الأداء فيها. وهو ما يحدث بالفعل في الدول المهتمة بذلك، حيث

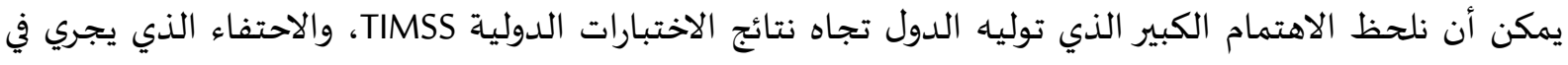

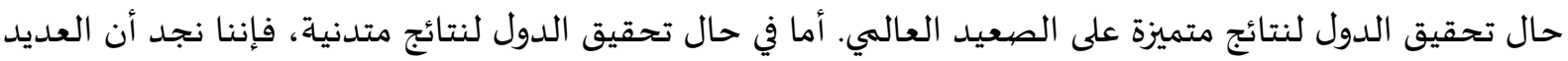

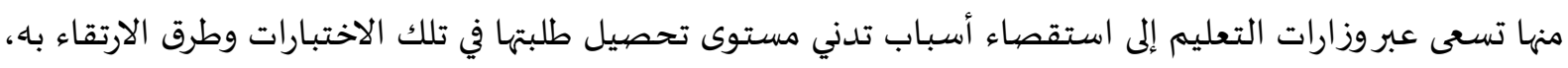

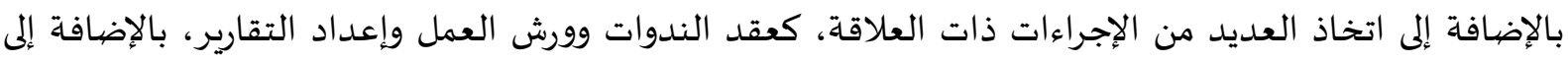
الاستعانة بالخبراء والمختصين.

وتعتمد المنظمة الدولية للتقويم التربوي IEA على منهجيات إحصائية متقدمة تم تطويرها في مجال القياس النفسي والتربوي، حيث استخدمت دراسة التوجهات الدولية في الرياضيات والعلوم TIMSS نظرية استجابة الفقرة

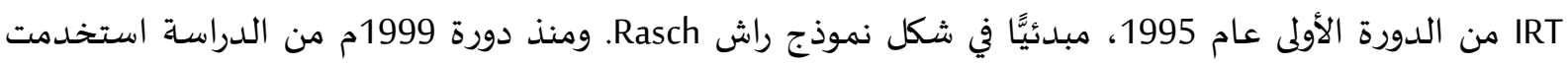

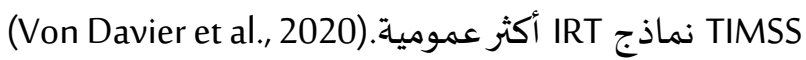
وتعتبر نظرية استجابة الفقرة Item Response Theory (IRT) أو نظرية السمات الكامنة Latent Traits Theory (LLT)

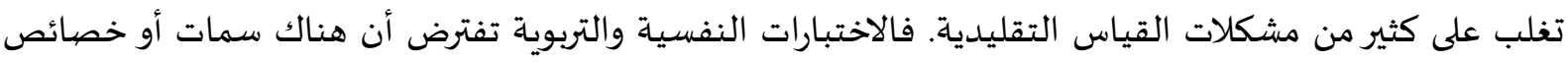

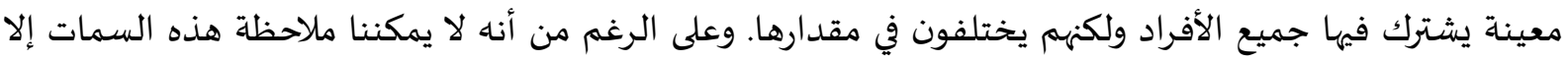

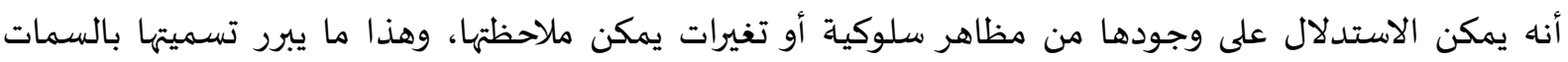
الكامنة (أبو عواد، 2018).

ونظرية استجابة الفقرة مثل النظرية الكلاسيكية تفترض أن الاستجابة على فقرات الاختبار تعزى إلى سمات

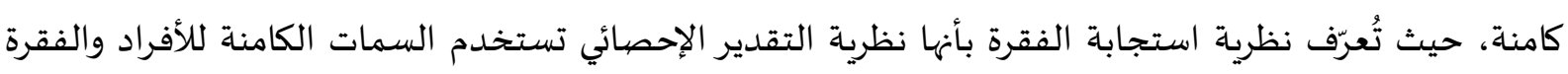

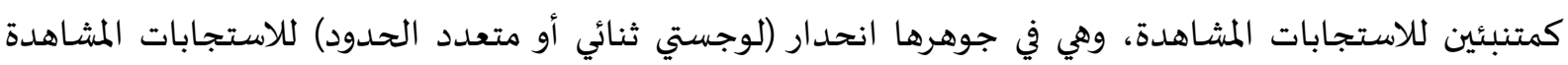

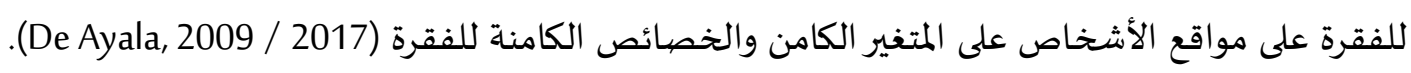
ويمكن وصف العلاقة بين احتمال الاستجابة الصحيحة لفقرة من الفقرات ومقياس القدرة بالمنحنى المميز

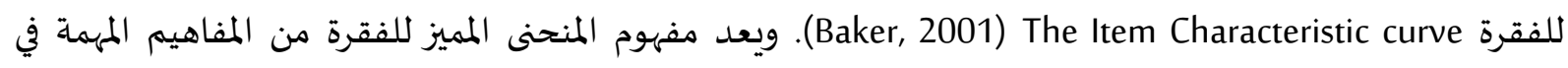

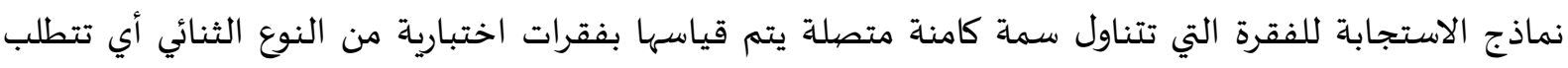

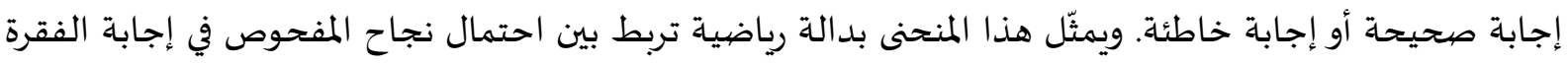

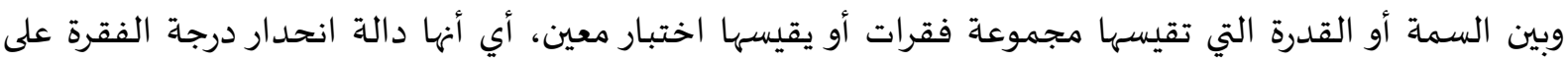

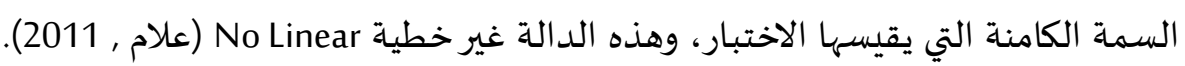
وتكمن أهمية نظرية استجابة الفقرة وتطبيقاتها في تحليل الفقرة؛ في التوصل إلى معالم فقرة ثابتة نسبيَّا لا لا

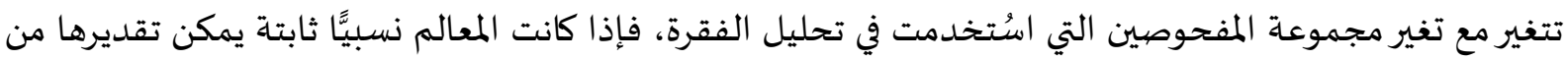
بيانات مجموعة واحدة ثم تطبيق هذه التقديرات بثقة على أية مجموعة من المفحوصين بمان فيها فيهم المجتمع الكلي

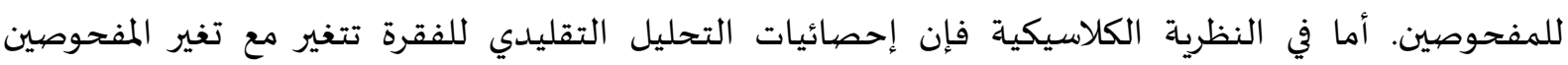

(Crocker \& Algina.2008/2017) وفي النظرية الكلاسيكية تتأثر خصائص مجموعة المفحوصين بخصائص الفقرات أي أن الدرجة الحقيقية والدرجة الملاحظة (True Score) الدرجة الحقيقية (True Score) ودرجة القدرة (Ability Score) مما يعني أن قدرة المفحوص ثابتة في موقف معين ولان تتأثر بخصائص الفقرات (Item Free) (عودة , 2010). 
ولتعزيز التكامل والتنسيق بما يحقق مستهدفات رؤية المملكة 2030 في رفع جودة التعليم والتدريب؛ اطلعت

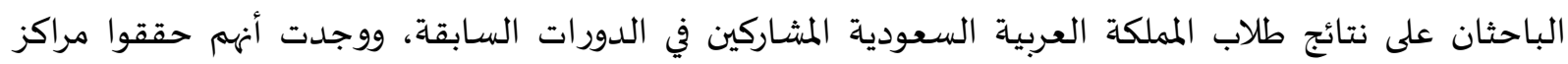

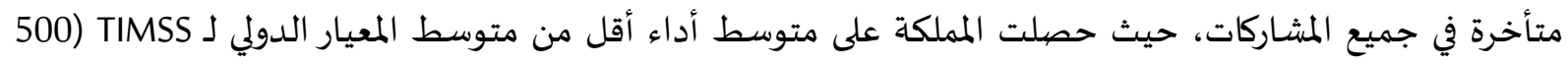

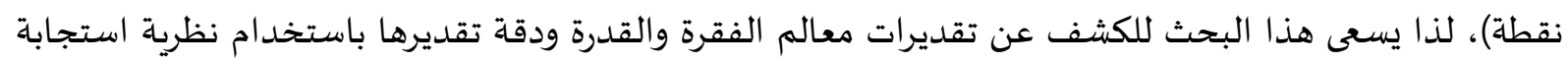
الفقرة لما تتميز باه من موضوعية ودقة في القياس مقارنة بالنظرية الكلاسيكية.

مشكلة الدراسة وأسئلتها:

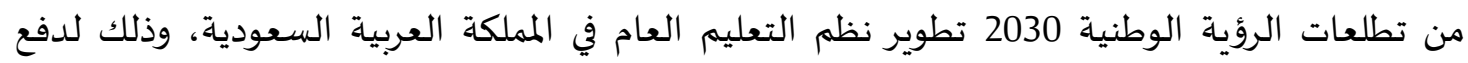
عجلة الاقتصاد الوطني، وتنويعا، وتحقيق التنمية المستدامة للمجتمع السعودي. كما أن وزارة التعليم تسعى أثناء

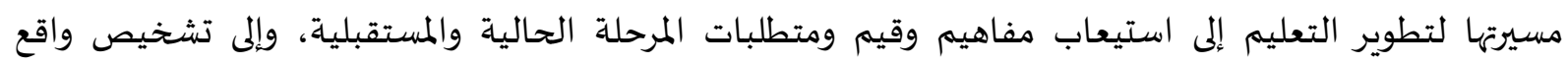

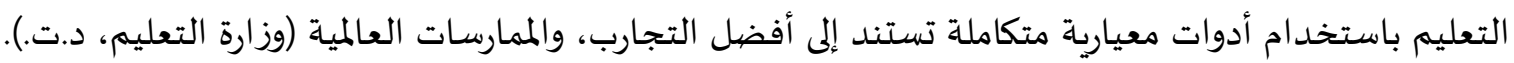
ومن منطلق التنافسية الدولية وتحقيق جودة التعليم؛ حرصت المملكة العربية السعودية على تفعيل

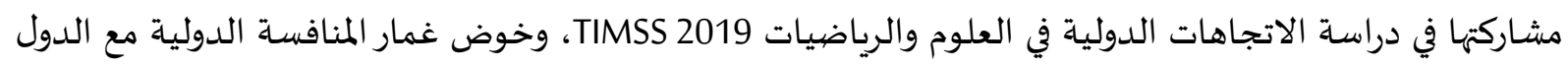

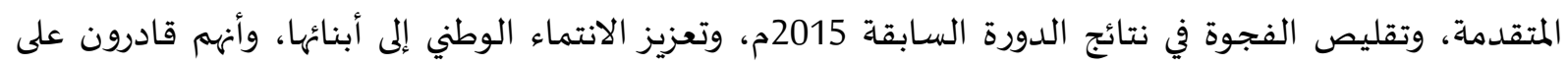
المنافسة وإحداث التغيير المنشود (وزارة التعليم، د.ت. وبناء على النتائج التي نشرتها المنظمة الدولية للتقويم التربوي IEA أصدرت التهات هيئة تقويم التعليم والتدريب

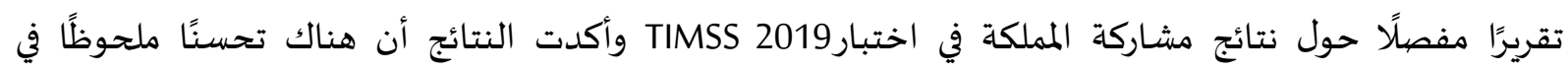

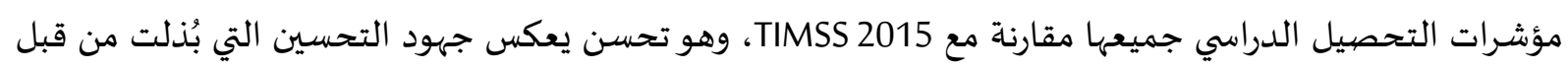

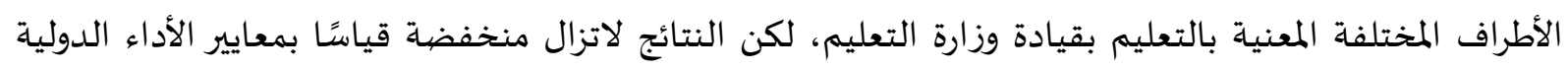

.(ETEC,2020)

ونشرت المنظمة في موقعها الرسمي جميع البيانات الخاصة بالاختبار الدولي TIMSS حتى تتيح للباحثين

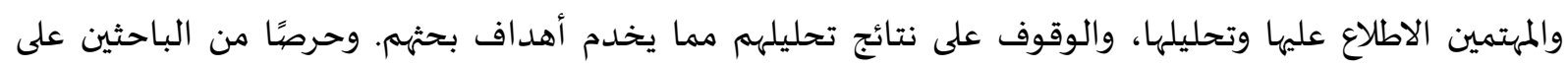

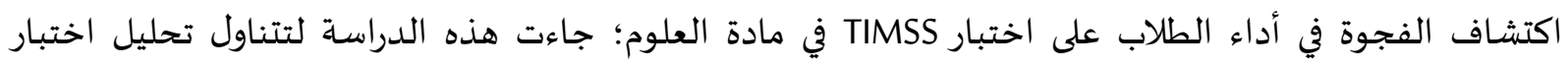
TIMSS باستخدام نظرية استجابة الفقرة للكشف عن دقة تقديرات معالم الفقرات لاختبار 2019 TIMSS 2019 والقدرة للمفحوصين وفق النموذج اللوجستي ثنائي المعلمة. لذا تتحدد مشكلة الدراسة في الأسئلة الآتية: 1- ما دقة تقدير معلمة الصعوبة لفقرات اختبار TIMSS لمادة العلوم للصف الثاني المتوسط وفق المقدة 2019

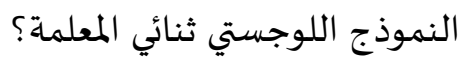

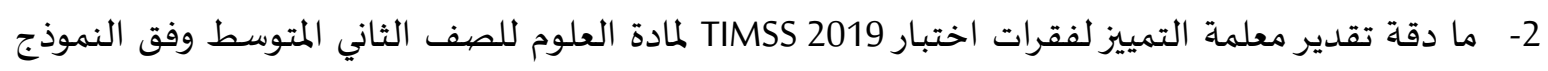
ثنائي المعلمة 3- ما دقة تقدير معلمة القدرة لأداء الطلاب المشاركين على اختبار TIMSS لمادة العلوم للصف الماند 2019

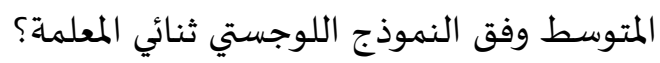
4- ما معاملات ثبات اختبار 2019 TIMSS: (الثبات الإمبريقي، وثبات الأفراد، وثبات الفقرات) لمادة العلوم

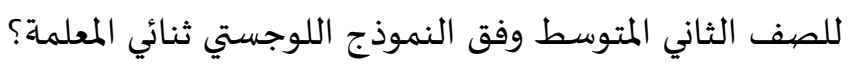


تهدف هذه الدراساة إلى:

1- الكشف عن دقة تقدير معلمة الصعوبة لفقرات اختبار TIMSS لمادة العلوم للصف الثاني المتوسط وفق

$$
\text { النموذج اللوجستي ثنائي المعلمة. }
$$

2- الكشف عن دقة تقدير معلمة التمييز لفقرات اختبار TIMSS لمادة العلوم للصف الثاني المتوسط وفق

النموذج اللوجستي ثنائي المعلمـة.

3- الكشف عن دقة تقدير معلمة القدرة لأداء الطلاب على اختبار2019 TIMSS لمادة العلوم للصف الثاني

$$
\text { المتوسط وفق النموذج اللوجستي ثنائي المعلمة. }
$$

4- الكشف عن معاملات ثبات اختبار2019 TIMSS: (الثبات الإمبريقي، وثبات الأفراد، وثبات الفقرات) لمادة

$$
\text { العلوم للصف الثاني المتوسط وفق النموذج اللوجستي ثنائي المعلمة. }
$$

الأهمية النظرياة:

تسهم هذه الدراسة في تقديم بحث تحليلي ومؤشرات كمية ذات دلالة للأداء على اختبار TIMSS الدولي، وذلك باستخدام النموذج اللوجستي ثنائي المعلمة المنبثق عن نظرية الاستجابة للفقرة والتي تحظى بأهمية كبيرة في مجال القياس.

تسهم هذه الدراسة في تسليط الضوء على ضرورة بناء الاختبارات التربوية وفق نظرية الاستجابة للفقرة للتغلب على عيوب النظرية الكلاسيكية في القياس.

دعم القاعدة النظرية للبحوث والدراسات في مجال نظرية الاستجابة للفقرة وفي الاختبارات الدولية TIMSS.

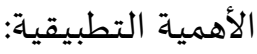

يتوقع الباحثان أن تتم الاستفادة من نتائج الدراسة في توجيه القائمين على العملية التعليمية في اتخاذ قرارات صائبة لتحسين مستوى الأداء على الاختبار. قد تفيد هذه الدراسة الجهات المختصة ببناء وتطوير الاختبارات في تحسين طريقة إعداد الاختبارات وبنائها،

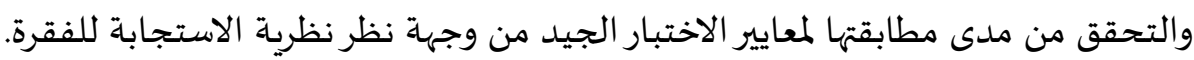

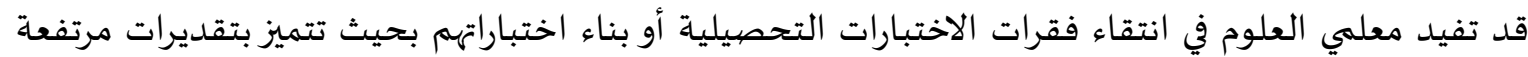
لمعالم الفقرات. يؤمل الباحثان أن تسهم هذه الدراسة في حث مشرفي ومعلمي العلوم على الاهتمام بمستويات الأسئلة التي تطرح

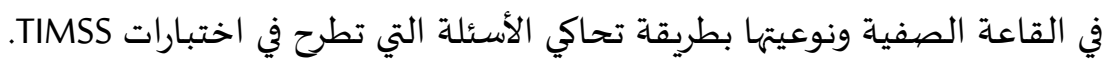

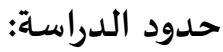

تقتصر هذه الدراسة على الحدود الآتياة:

الموضوعية: دقة تقدير معالم الفقرات والقدرة وفق النموذج اللوجستي ثنائي المعلمة لاختبار 2019 TIMSS

لمادة العلوم. البشرية: طلبة الصف الثاني المتوسط المشاركين في الاختبار الدولي 2019 TIMSS. 
المكانية: المدارس المشاركة في الاختبار الدولي TIMSS 2019 في المملكة العبية السعودية. الزمانياة: تم تطبيق هذه الدراسة خلال العام الدراسي 2020 / 2021 م.

\section{مصطلحات الدراسـة:}

- دقة التقديرAccuracy of Estimate، هي: "تعبير يشير إلى جودة التقدير للمعالم والقدرة التي تميزها الاحتمالية الكبيرة في أن التقدير قريب من القيمة الحقيقية للمعلم، باستخدام الأخطاء المعيارية في التقدير" (الدرابسه

وعودة، 2012: 63).

- ل الصعوبة difficulty of the item، هي: "نقطة على مقياس القدرة عندما يكون احتمال الاستجابة الصحيحة يساوي 0.50" (Baker, 2011: 22)

O متُعرّف إجرائيَّا بأنها: القيمة التي تندرج على متصل السمة ويكون احتمال إجابة الفقرة عندها إجابة صحيحة مسـاويًّا 50\%.

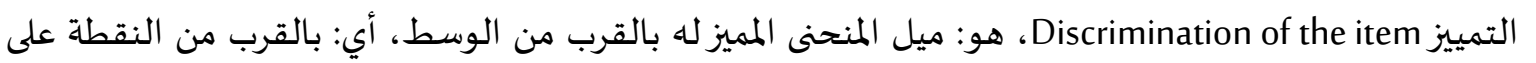

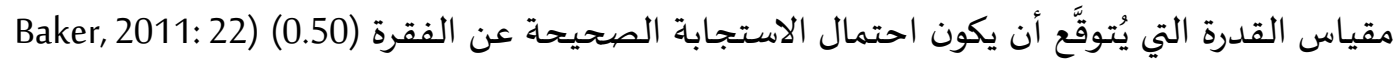

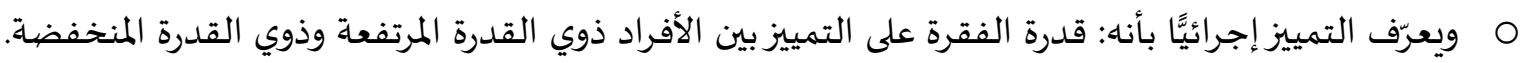

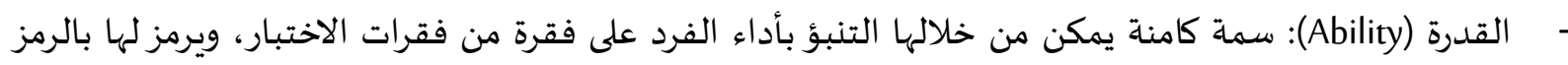

$$
\text { ثيتا } \theta \text { (علام، 2005: 47). }
$$

O مُتُعرّف القدرة إجرائيًا بأها: قيمة يتم تقديرها تعظم أرجحية استجابات الفرد عن فقرات الاختبار.

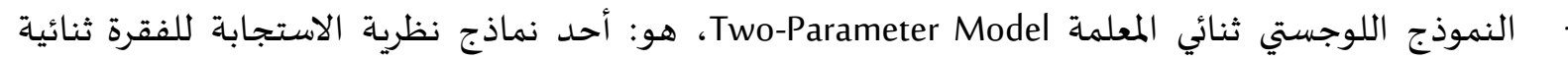

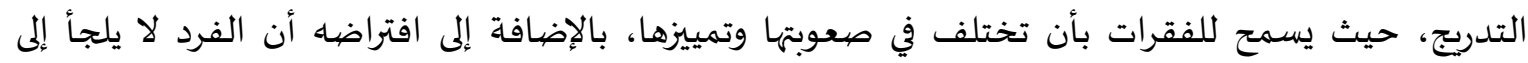
التخمين العشوائي في إجابته عن فقرات الاختبار (علام، 2011: 700)

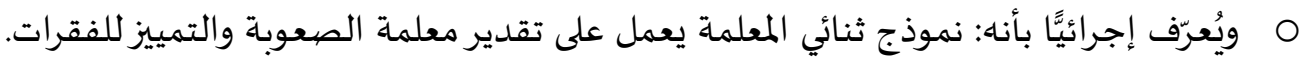
- اختبار TIMSS، هو اختبار دولي لتقييم تحصيل الطلاب بمادتي الرياضيات والعلوم للصف الرئ الرابع والثامن الأساسيين، وتشرف عليه الرابطة الدولية لتقييم التحصيل التربوي.

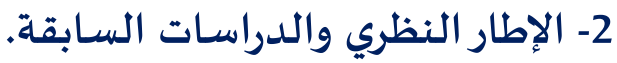

أولا- الإطار النظري: دراسة الاتجاهات الدولية في الرياضيات والعلوم TIMSS

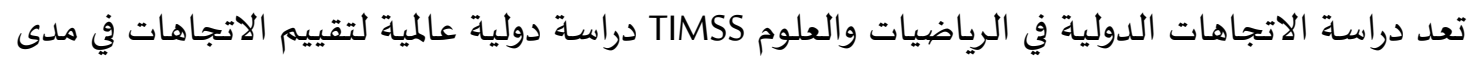
تحصيل الطلاب والطالبات في مادتي الرياضيات والعلوم عند طلاب الصفين: الرابع الابتدائي والثامن (الثاني المتوسط). حيث تسعى معظم نظم التعليم في العالم للمشاركة في هذه الدراسات والاختبارات، إما بهدف إبراز تميز

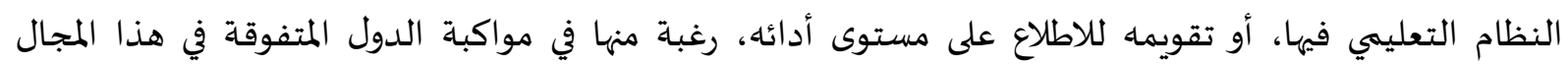
.(ETEC,1439)

بدأ تطبيق دراسة الاتجاهات الدولية في الرياضيات والعلوم TIMSS عام 1995م، حيث تعقد بشكل دوري

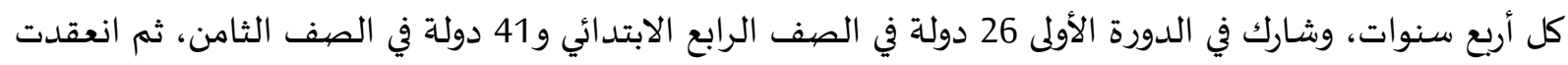
دورتها الثانية في عام 1999م، وشارك فيها 38 دولة في الصف الثامن، ولم يتم تطبيق الدراسة على الصف الرف الرابع 
الابتدائي. وكانت الدورة الثالثة للدراسة في عام 2003م، وشارك فهها 25 دولة في الصف الرابع الابتدائي، و46 دولة

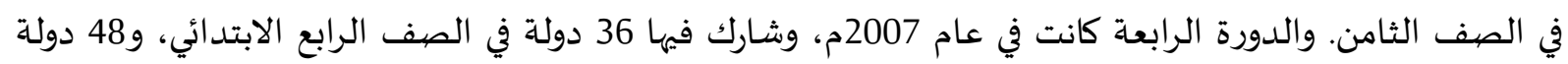

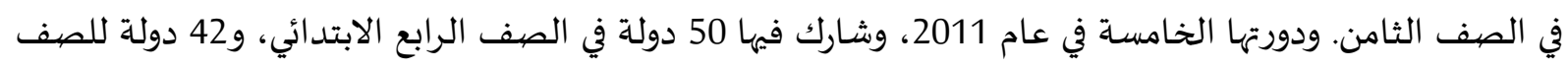

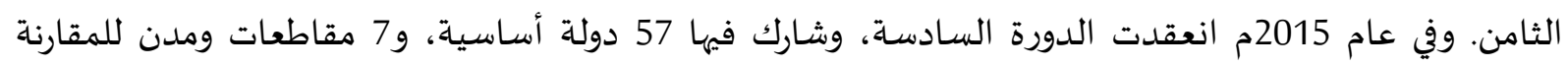
(Benchmarking)، منها 49 دولة شاركت في الرياضيات و47 دولة دولة شاركت في العلوم للصف الرابع الابتدائي، و39

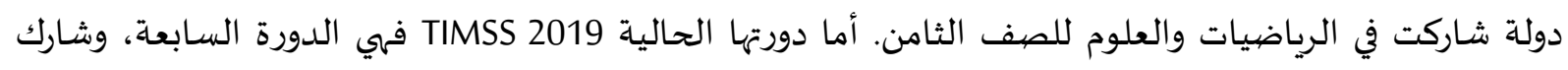

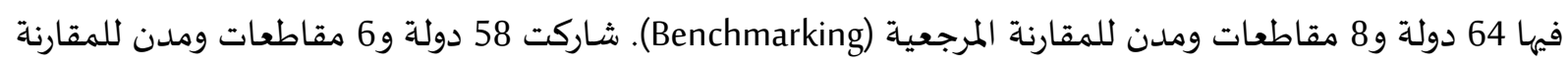

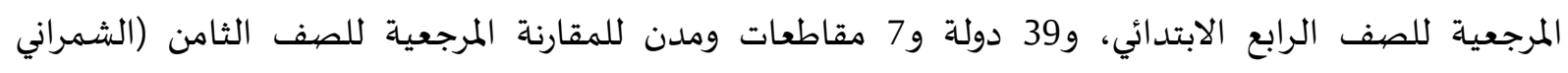
وآخرون، Mullis et al., 2020؛2016).

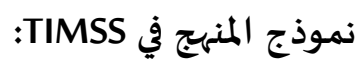

تبنت دراسة التوجهات الدولية في الرياضيات والعلوم TIMSS نموذجًا للمنهج يركز بشكل رئيس على كيفية

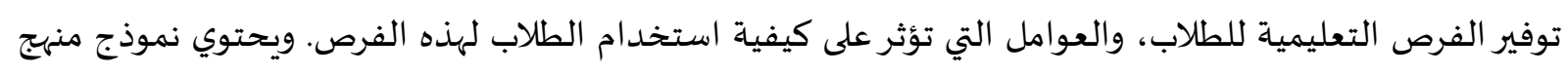
TIMSS المنهج المقصود Intended Curriculum: يقصد باه المنهج الذي يحدد على المستوى الوطني للدولة والذي يراعي الهوية والمحتوى الاجتماعي والتعليمي. المنهج المنفذ Implemented Curriculum: يقصدي به المنهج الذي يطبق في المدرسة من قبل المعلم حيث يراعي المحتوى المدرسي والبيئة المدرسية. المنهج المكتسب Attained Curriculum: يقصد به المنهج الذي يتعلمـ الطالب ويكتسب من خلاله بعض

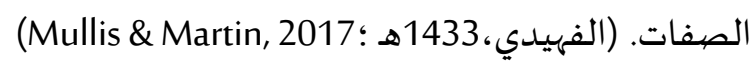
يتبين من خلال نموذج منهج TIMSS أهنا دراسة شاملة تعكس مدى الجودة في النظام التعليمي للدول

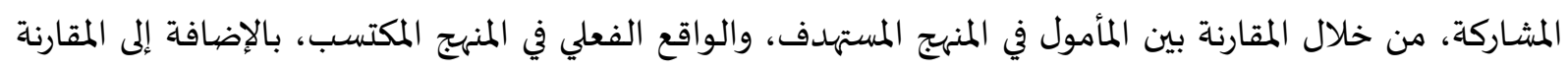

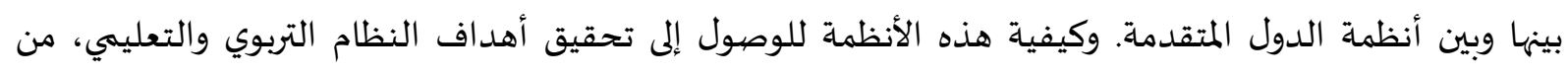
خلال معرفة مواطن القوة وتعزيزها، ومعرفة مواطن الضعف والعمل على معالجتها (السليماني،2016).

مجالات TIMSS 2019

تم تحديث أطر تقييم TIMSS لعام 2019 من تلك المستخدمة في عام 2015. حيث تم تحديد مجالين

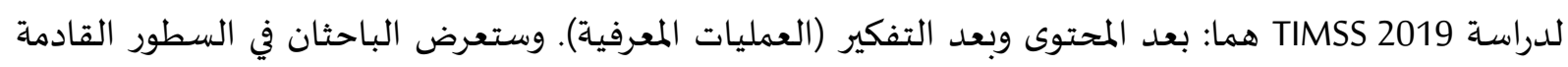
المجالات التي تخص العلوم للصف الثامن (الثاني المتوسط) كما ورد في الإطار النظري (TIMSS Science Framework)

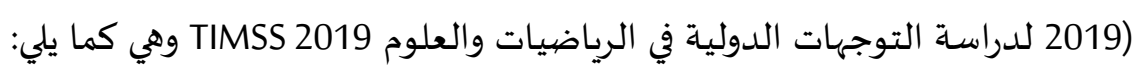
أولًا: مجالات المحتوى المعرفي Content Domains: تحدد أربعة مجالات محتوى رئيسية للمحتوى العلهي الميات

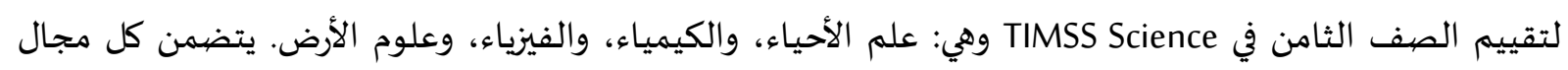

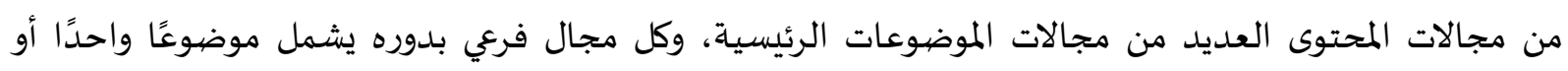

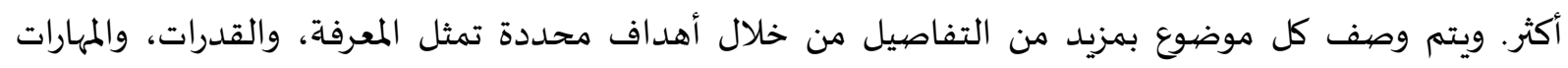

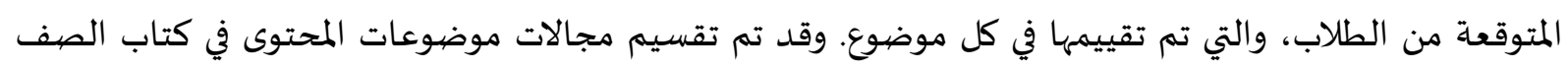


الثامن إلى نسب مئوية، ويوضح الجدول (1) النسب المئوية المستهدفة لكل مجال من مجالات المحتوى الأربعة في التقييم العلمي Mullis \& Martin, 2017). TIMSS 2019 (1).

جدول (1): النسبة المئوية لمجالات موضوعات المحتوى المستهدفة في دراسة 2019 TIMSS

\begin{tabular}{|c|c|}
\hline النسبة المئوية & مجالات موضيوعات المحتوى للصـف الثامن \\
\hline$\% 35$ & الأحياء \\
\hline$\% 20$ & الكيمياء \\
\hline$\% 25$ & 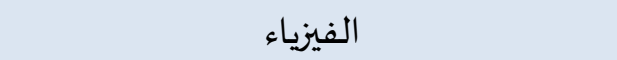 \\
\hline$\% 20$ & 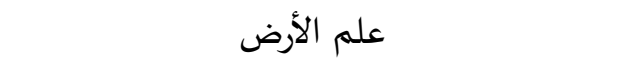 \\
\hline
\end{tabular}

ثانيًا: مجال العمليات المعرفية Cognitive Domains: ينقسم مجال العمليات المعرفية إلى ثلاثة مجالات فرعية تصف عمليات التفكير التي يُتوقع من الطلاب المشاركة فيها للإجابة بشكل صحيح عن الفقرات التي يغطيها

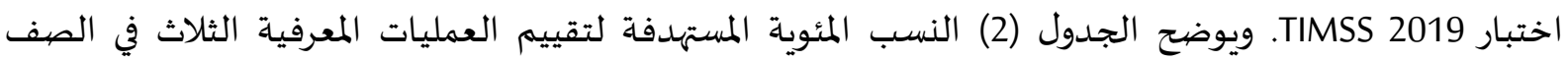
الثامن. (Mullis \& Martin, 2017).

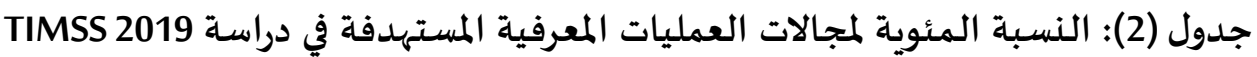

\begin{tabular}{|c|c|}
\hline النسبة المئوية & مجال العمليات المعرفية للصفف الثامن \\
\hline$\% 35$ & المعرفة \\
\hline$\% 35$ & 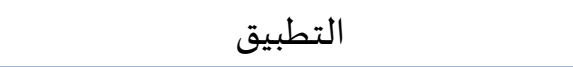 \\
\hline$\% 30$ & الاستدلال \\
\hline
\end{tabular}

أدوات دراسة التوجهات الدولية في الرياضيات والعلوم 2019 TIMSS: Mullis \& Martin, تتضمن الدراسة عدة أدوات خاصة بها كما ورد في (حسان، 2013؛ السليماني، 2016؛

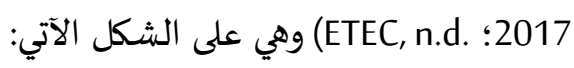

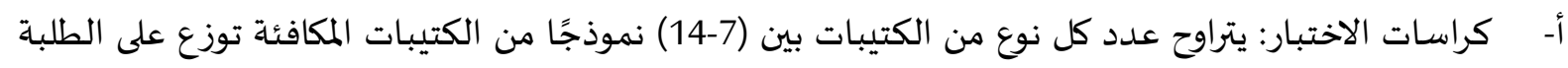

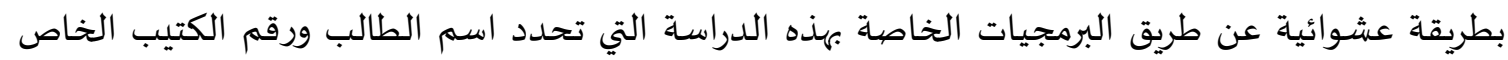

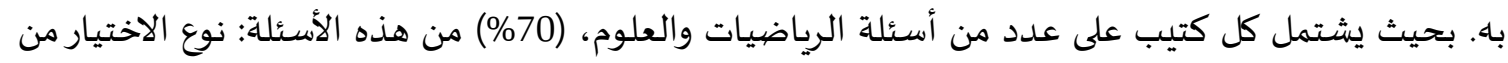

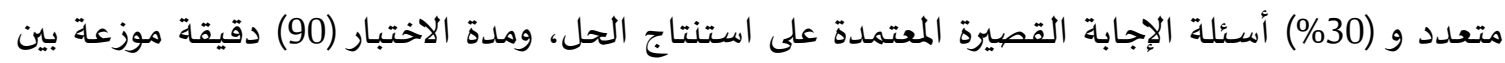

$$
\text { جلستين (الرياضيات - العلوم). }
$$

ب- استبانات الدراسة: تفيد استبانات الدراسة التي تسهم فهيها الدول المشاركة في تقديم معلومات مهمة لموسوعة

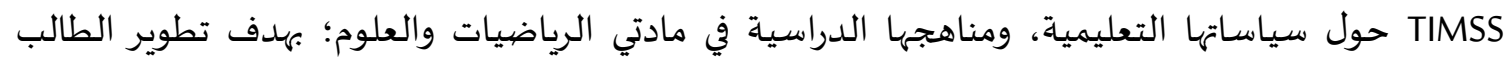

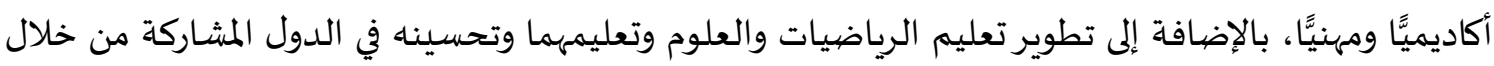

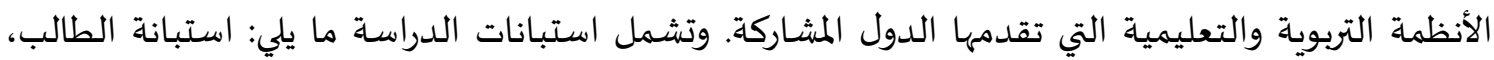
استبانة المعلم، استبانة المدرسـة، استبانة المنزل، واستبانة المنهج. (السليماني، 2016).

مشـاركة المملكة العربية السعودية في دراسة التوجهات الدولية في الرياضيات والعلوم TIMSS: تستهدف دراسة التوجهات الدولية في الرياضيات والعلوم الصفين: الرابع والثامن (الثاني المتوسطات الأساسيين في الدول المشاركة، حيث تقوم كل دولة مشاركة باختيار أحد الصفين أو كليهما معًا للمشاركة. وكانت أول 
مشاركة للملكة العربية السعودية في دراسة التوجهات الدولية في الرياضيات والعلوم TIMSS في الدورة الثالثة عام

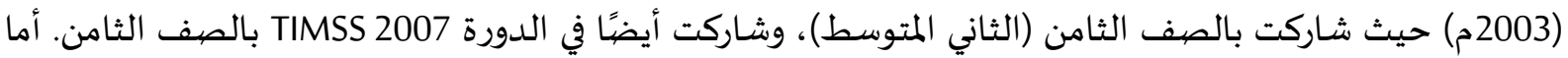

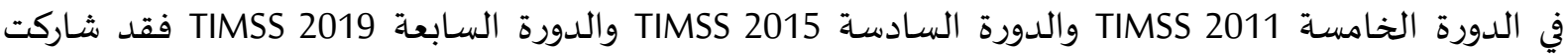
المملكة العربية السعودية بالصفين: الرابع الابتدائي والثامن (الثاني المتوسط) (السليماني، 2016).

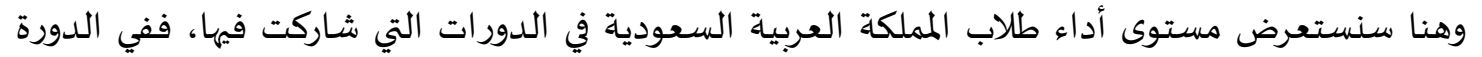
الثالثة TIMSS 2003 كأول مشاركة للمملكة العربية السعودية جاء ترتيب الطلاب في الموقع (39) من بين (46) دولة مُشاركة في الدراسة، بمتوسط أداء مقداره (398) بأقل بـ (76) نقطة من المتوسط الدولي (474)، وفي الدورة الرابعة

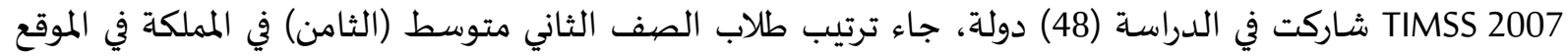

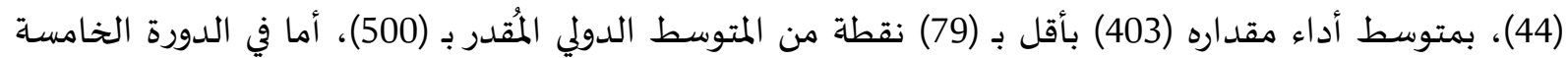

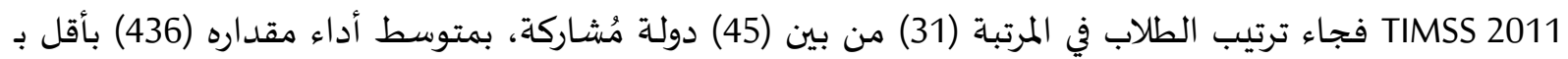

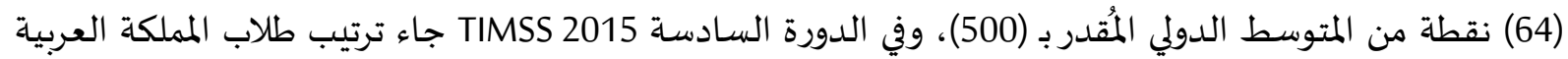
السعودية في المرتبة (35) من بين (39) دولة مشاركة في الدراسة، بمتوسط أداء مقداره (396) بأقل من المتوسط

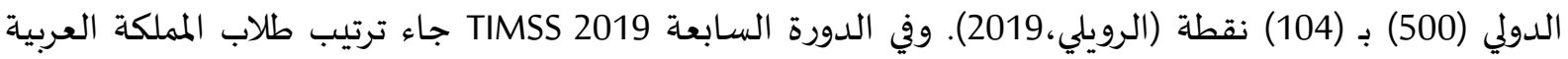
السعودية في المرتبة (35) من بين (39) دولة مشاركة في الدراسة، بمتوسط أداء مقداره (431) بأقل من المتوسط الدواء

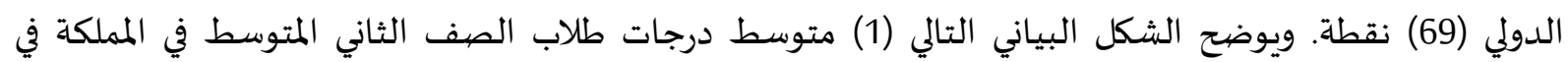
العلوم وفق TIMSS من T2011 إلى 2019 (ETEC,2020):

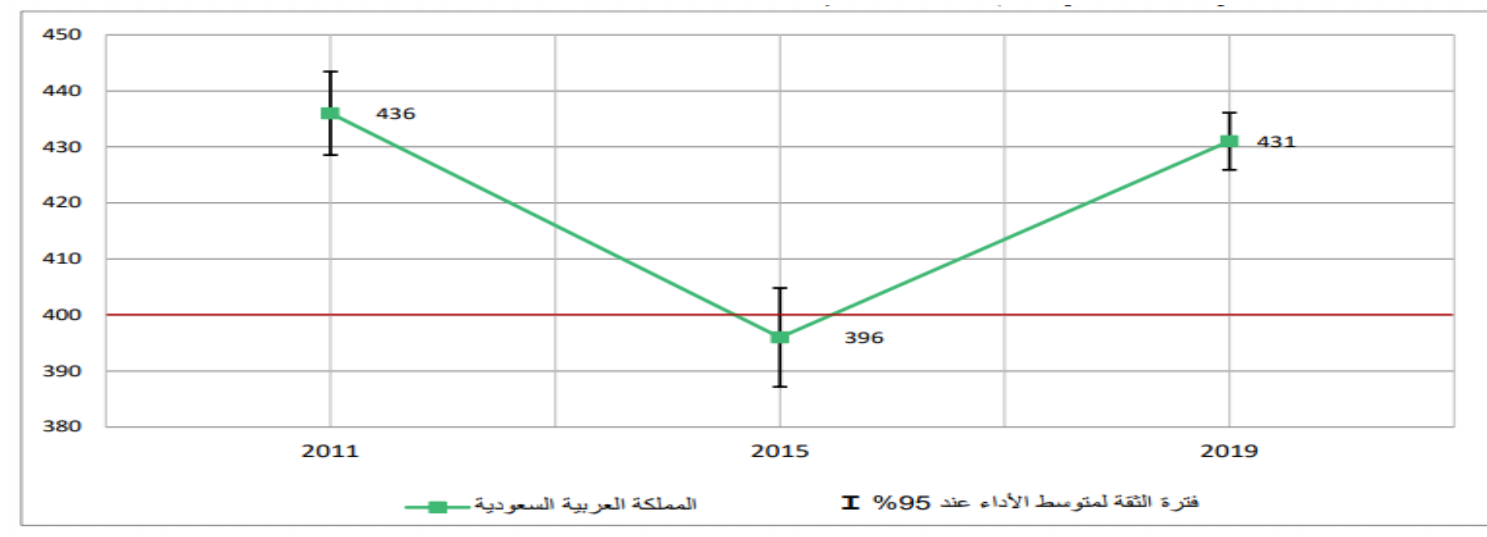

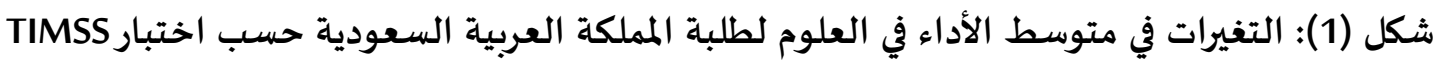

ثانياً- الدراسات السابقة: فيما يلي عرضٌ لمجموعة من الدراسات السابقة ذات الصلة بموضوع هذه الدراسة، من خلال دراسات

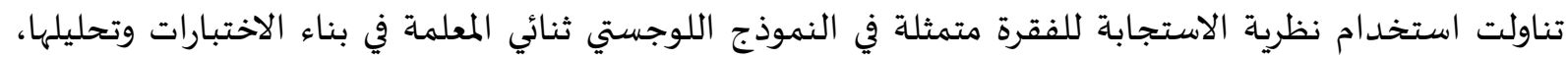

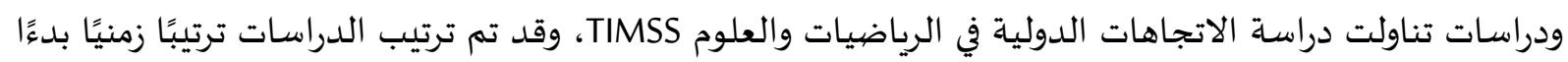
من الأحدث وانتهاءً بالأقدم.

- ماسـة جراح (2020): هدفت هذه الدراسة إلى التعرف على أنماط الاستجابة في الاختبار الدولي ( TIMSS,

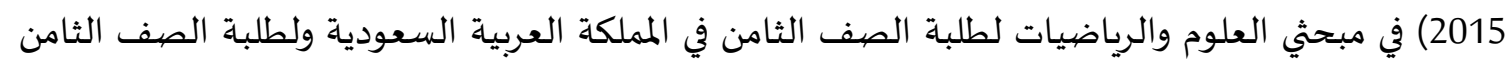
من دولة سنغافورة باستخدام مؤشرات مطابقة الشخص (مؤشر التمكن، ومؤشر سوء الفهم، ومؤشر والتر

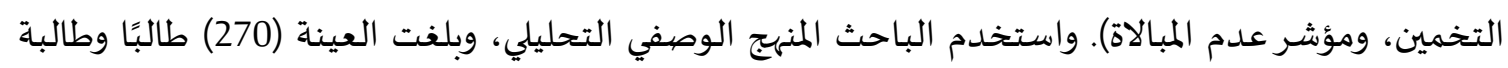

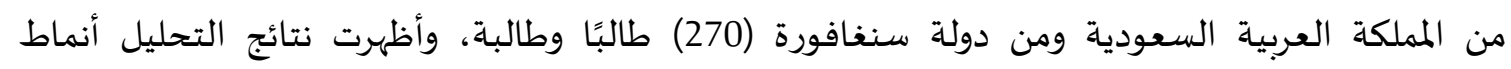


الاستجابة لبيانات دولة سنغافورة لمبحث العلوم والرياضيات؛ أن 92\% و94\% على التوالي صنفت كأنماط استجابة طبيعية، وأن 8\% و6\% على التوالي صنفت كأنماط استجابة غير طبيعية. بينما أظهرت نتائج تحليل

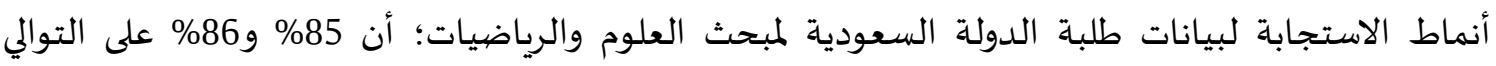

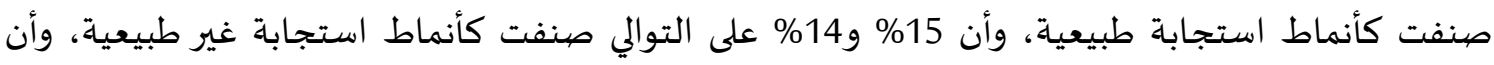

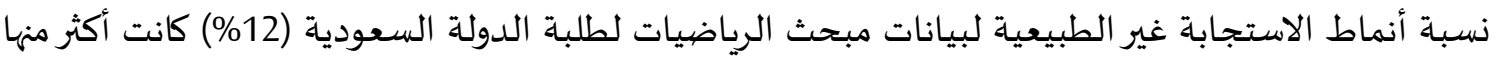

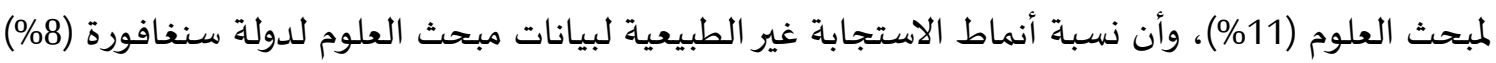
أكثر منها لمبحث الرياضيات (6) (1).

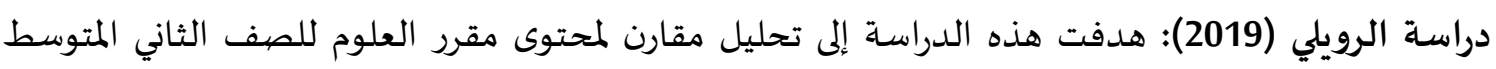

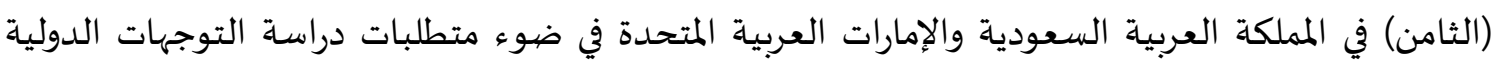

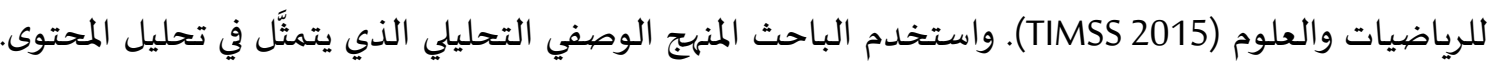

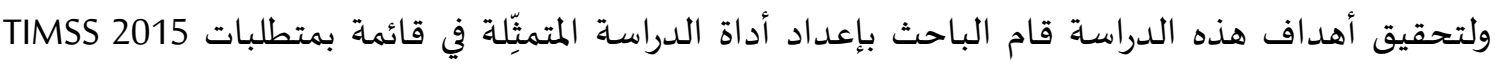

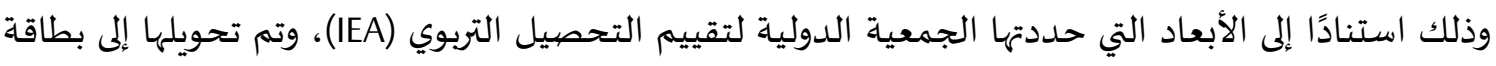

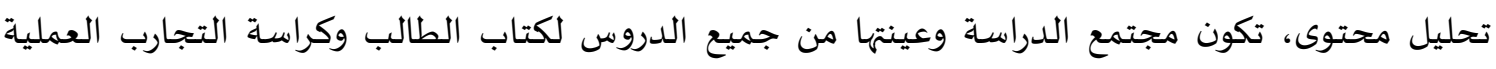

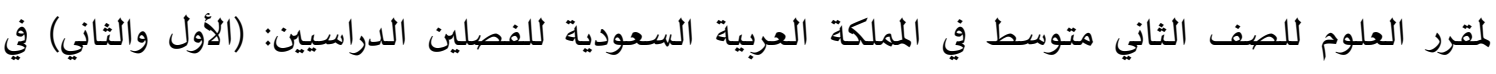
طبعتهما لعام 1438هـ/2017م، وكتاب العلوم للصف الثامن في الإمارات العربية المتحدة بفصيوله الثلاثة:

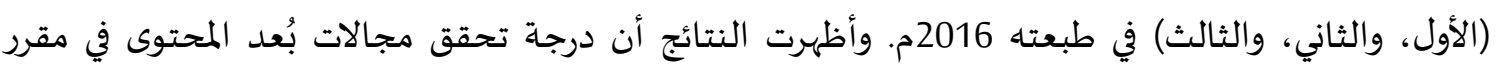

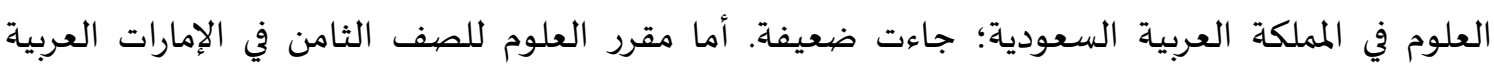
المتحدة، فجاء بدرجة تحقق متوسطة. أما متطلبات الماتعلة المتعلقة بتحقق مجالات بُعد التفكير في مقرر العلوم للصف الثاني متوسط في المملكة العربية السعودية، فجاءت بدرجة متوسطة وبنسبة تضمين

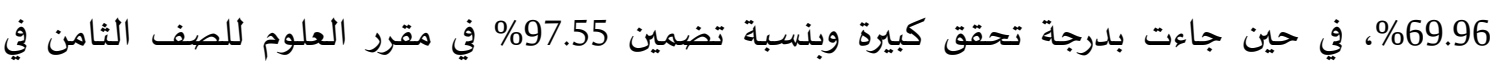
الإمارات العربية المتحدة. دراسة العنزي (2019): هدفت هذه الدراسة إلى التعرف على أثر شكل فقرات الاختيار من متعدد والصواب

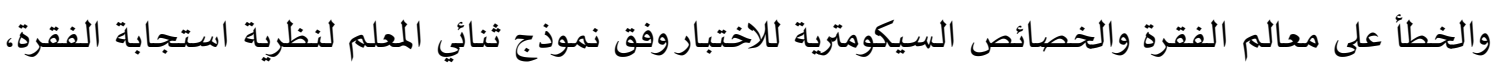

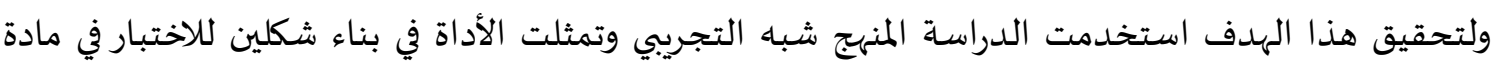
الحاسب الآلي: الاختيار من متعدد والصواب والخطأ، حيث تكون كل شكل من شكلي الاختبار في صورته

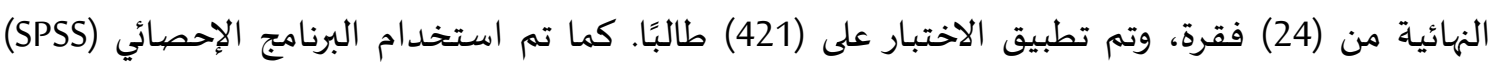

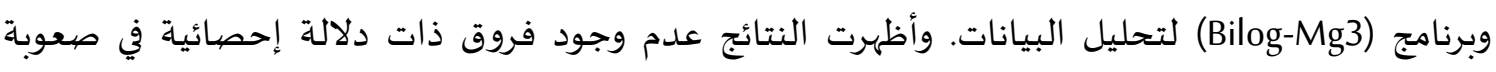

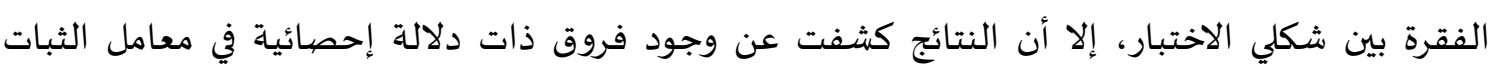
التجريبي بين شكلي الاختبار. دراسة المرواني (2019): هدفت هذه الدراسة إلى الكشف عن أثر موقع البديل الصحيح في اختبار اختيار من

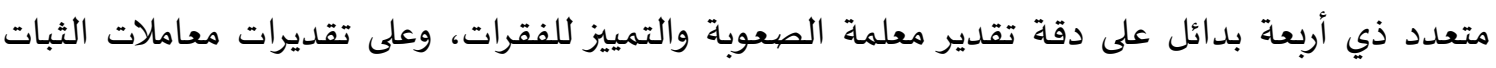

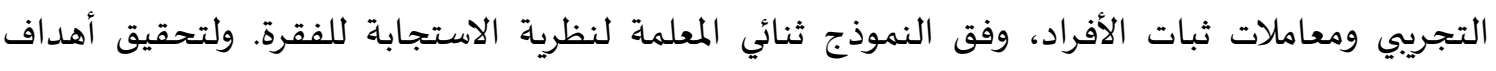

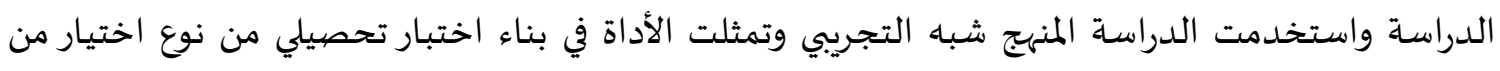

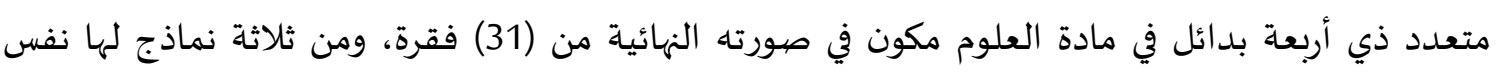

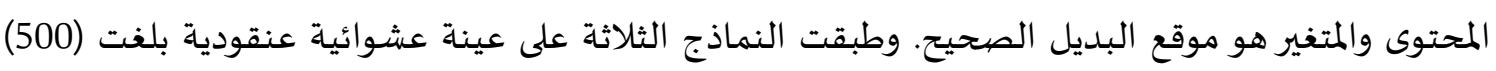


طالبة من طالبات الصف الثالث متوسط في مدينة ينبع. وتم استخدام البرنامج الإحصائي (SPSS) وبرنامج

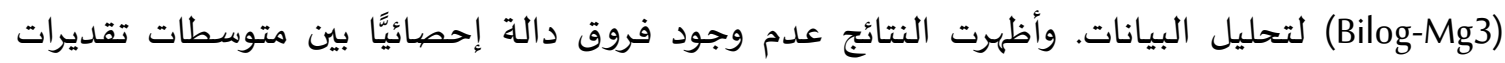
معاملات ثبات الأفراد تعزى إلى موقع البديل الصحيح. دراسة السلامي (2018): هدفت هذه الدراسة إلى بناء اختبار محكي المرجع في الرياضيات باستخدام نظريات

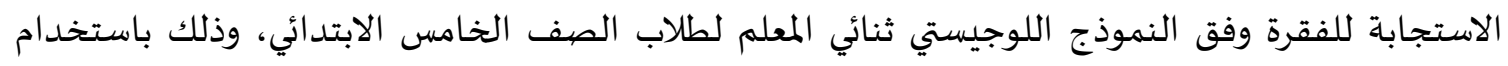

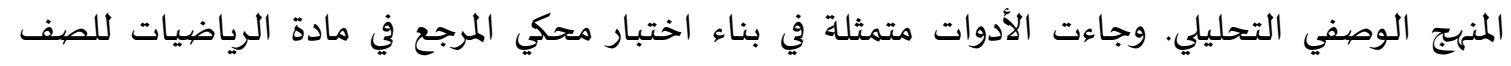

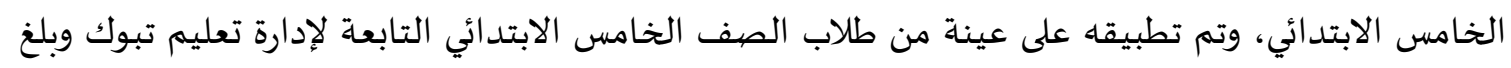

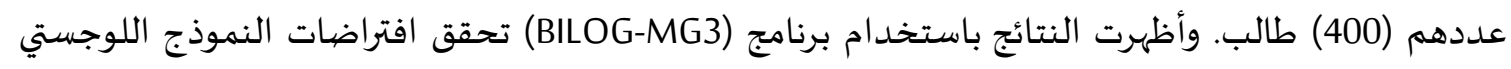
ثنائي المعلم ومطابقة (32) فقرة. وتم حذف الفقرات الستة غير المطابقة للنموذج اللوجيستي ثنائي المعلم،

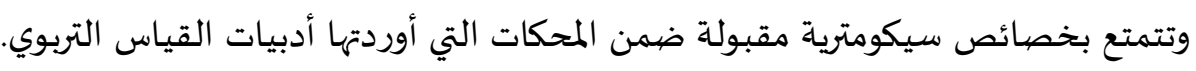

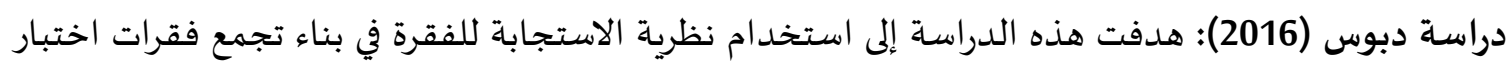

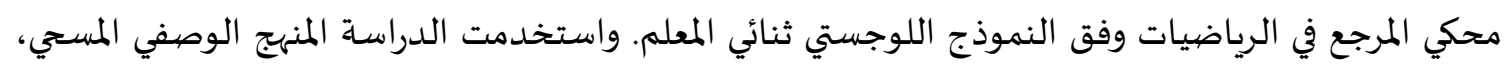

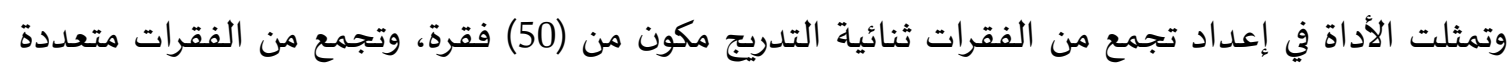

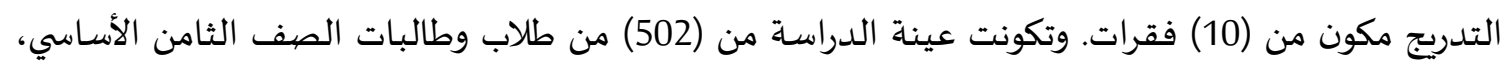

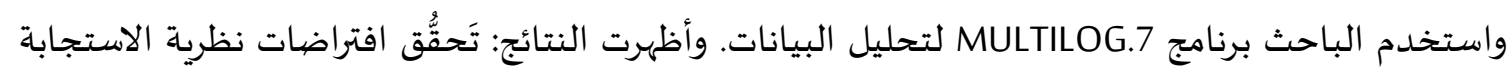

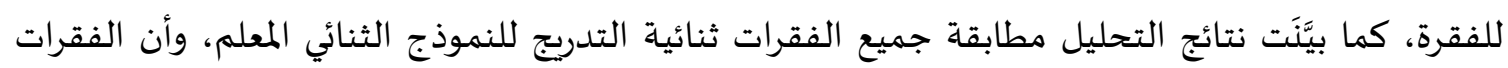

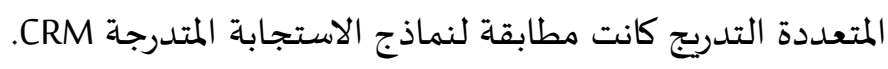
دراسة Shawn (2012) هدفت هذه الدراسة إلى إجراء تقييم مستقل لعينة ممثلة من فقرات اختبار TIMSS في العلوم. واستخدمت الدراسة المنهج الوصفي وتمثلت الأداة في بيانات اختبار حيث تم تطبيقه على 16009 طالب في الصف الثامن من 50 دولة. يتكون التقييم من ثلاثة مكونات: أولًا:

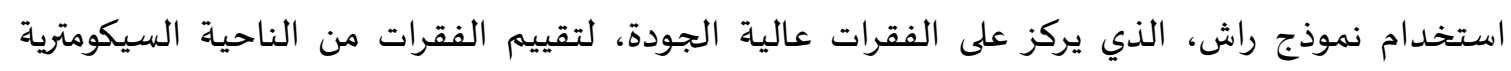

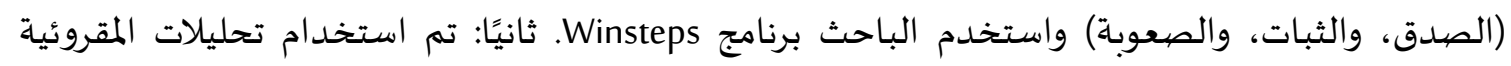

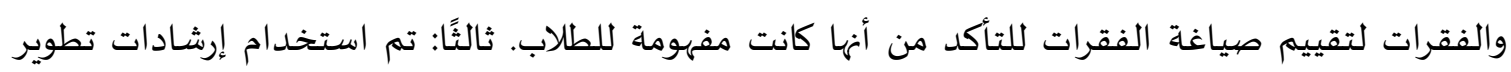

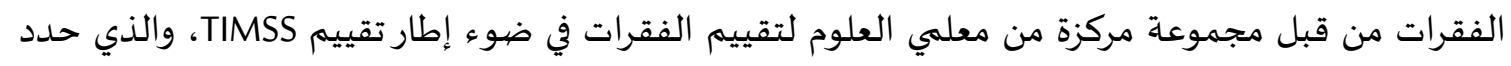

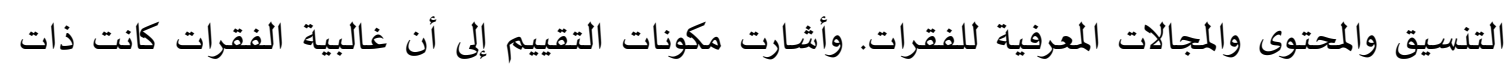

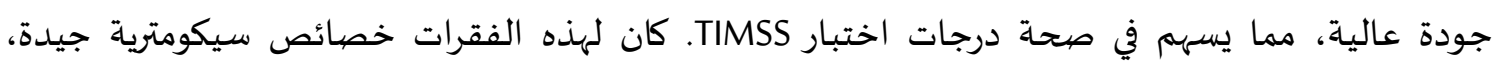

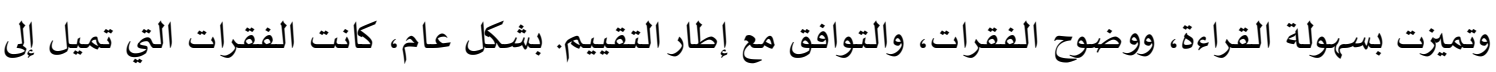

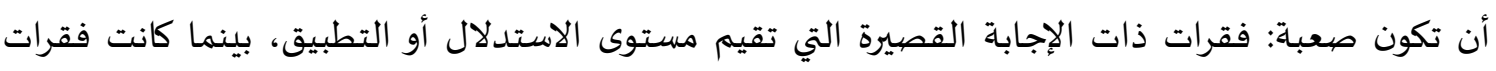

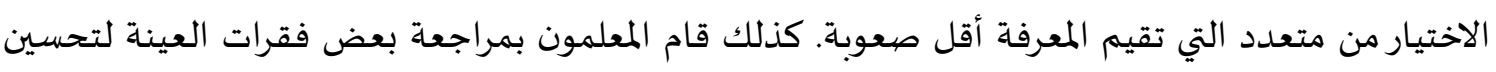

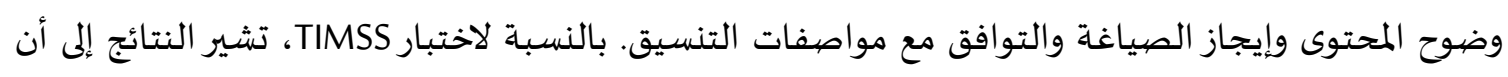

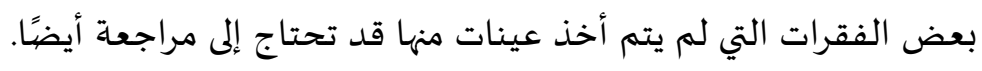

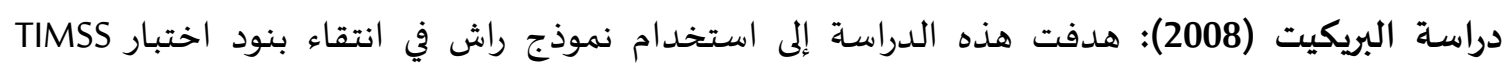

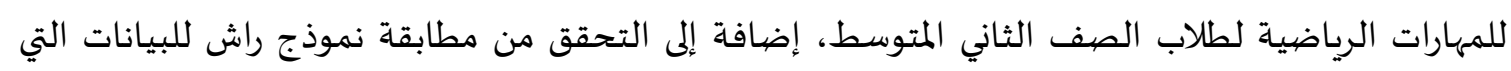

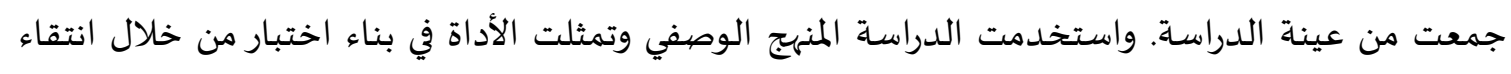

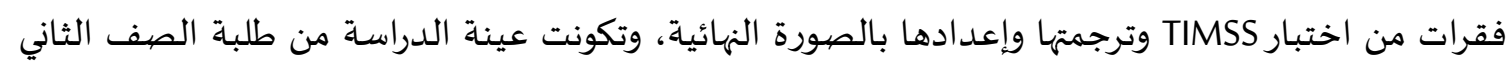


المتوسط، حيث تم تطبيق الاختبار على (670) طالبًا بمدينة تبوك. ولتحليل نتائج الدراسة استخدم الباحث

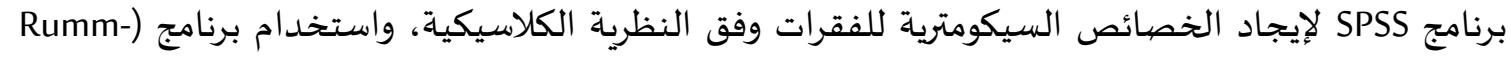

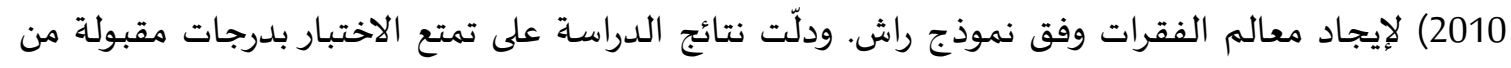

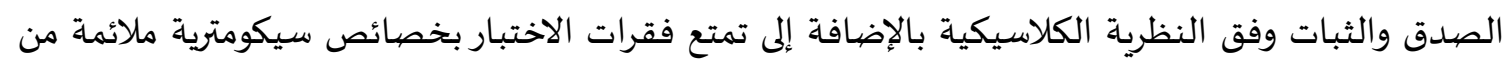
حيث مستوى الصعوبة والتمييز. وتمت مطابقة بيانات الاختبار إلى نموذج راش وأفرز التحليل (18) فقرة مطابقة لنموذج راش أحادي المعلمة.

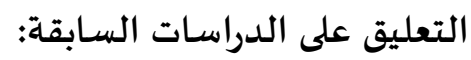

تبيّن من خلال عرض الدراسات السـابقة ذات الصلة الاهتمام الكبير بنظرية الاستجابة للفقرة؛ أنّ لها دقةً

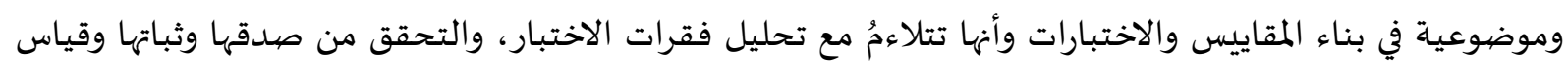

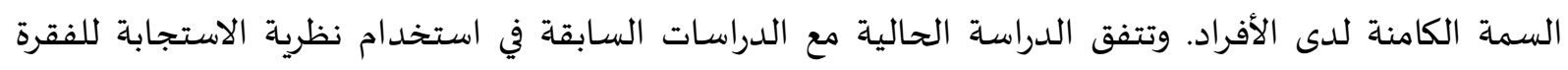
متمثلة في النموذج اللوجستي ثنائي المعلمة مثل: دراسات؛ دبوس، 2016؛ والسكالامئ، والمرواني، متمثل، 2019.

أما بالنسبة لمنهج الدراسة، فتتفق الدراسة الحالية مع معظم الدراسات السابقة في المنهج الوصفي التحليلي. كذلك، تباينت الأدوات المستخدمة في الدراسات السابقة، فبعضهم استخدم اختبار TIMSS كأداة للدراسة

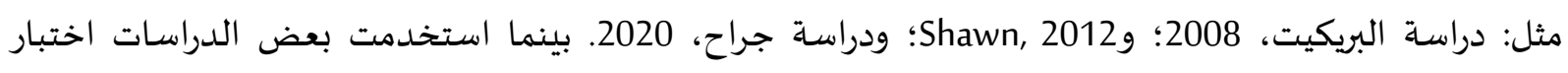

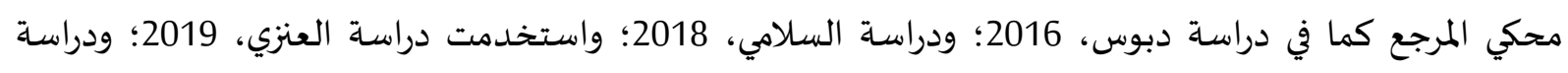

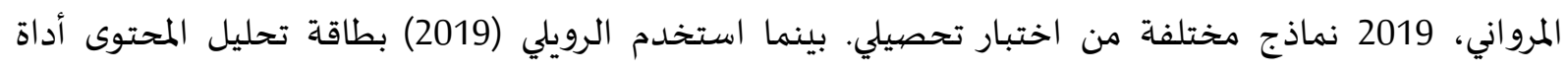

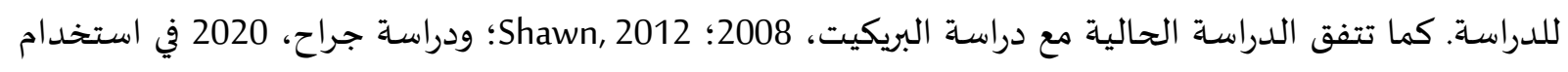
اختبار TIMSS أداة للدراسـة.

أما بالنسبة للعينة، فكانت عينة أغلب الدراسات السابقة من فئة الطلاب، وتباينت من حيث المرحلة

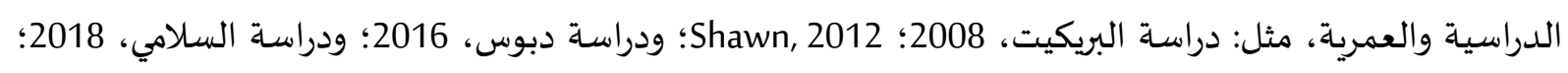

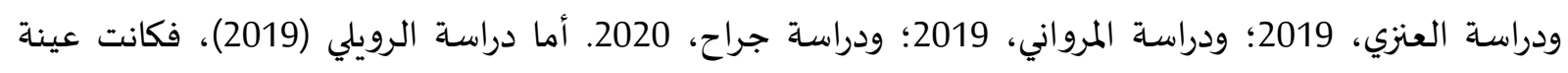

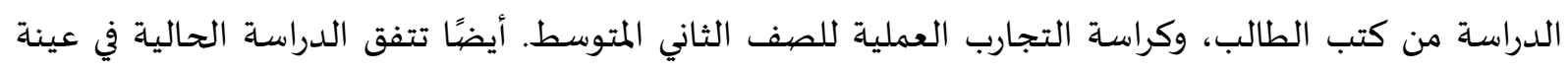

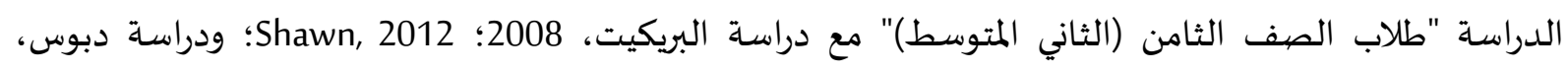
2016؛ ودراسة جراح، 2020. كذلك، تتفق الدراسة الحالية مع بعض الدراسات السابقة في البرنامج الإحصائي (BILOG-MG3) المستخدم

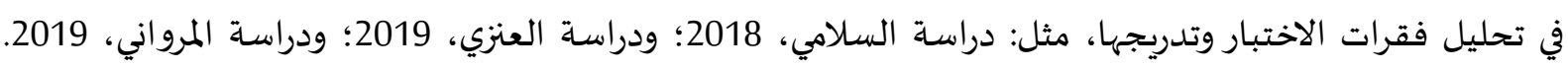

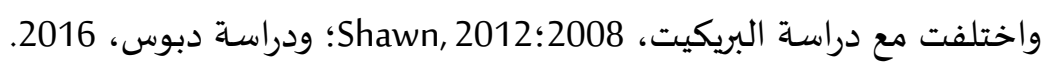
أجمعت معظم الدراسات السابقة على أن نماذج نظرية الاستجابة للفقرة تستند إلى افتراضات قورية الفية ترتكز

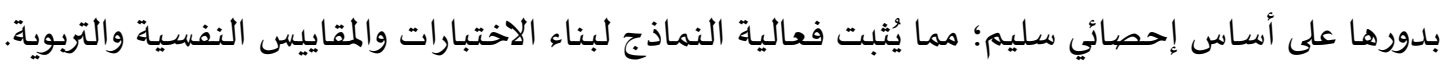

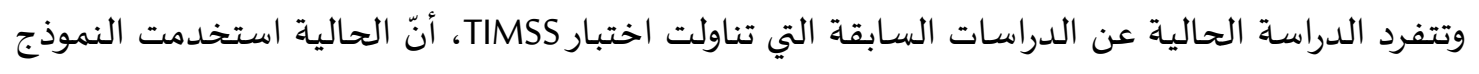

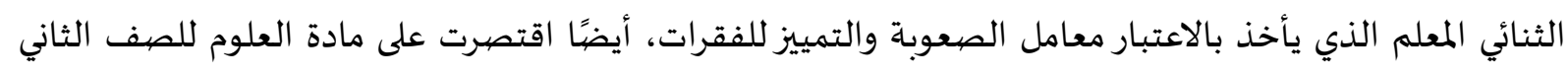
المتوسط. 


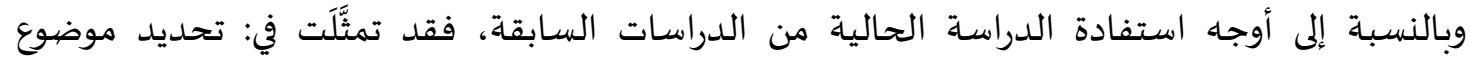

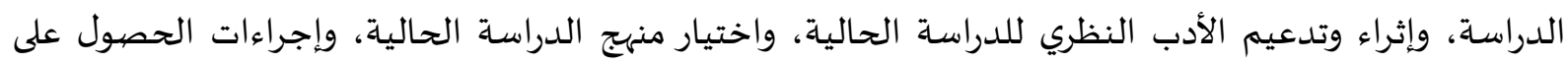
البيانات، وتفسير النتائج التي تم استخلاصيها.

3- منهجية الدراسـة وإجراءاتها.

منهج الدراسـة:

نظرًا لطبيعة الدراسة وبياناتها استخدم الباحثان المنهج الوصفي التحليلي، وهو أسلوب من أساليب المنهج

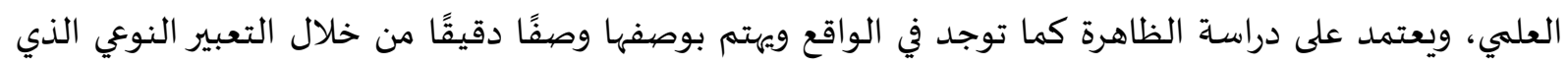

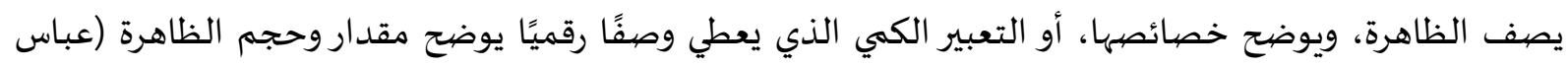
وآخرون، 2007).

مجتمع الدراسة:

تكون مجتمع الدراسة من جميع طلبة الصف الثاني المتوسط المشاركين في اختبار 2019 TIMSS في المملكة

العربية السعودية والبالغ عددهم 5680 طالبًا وطالبة اختيروا بشكل عشوائي من 209 مدرسة (ETEC, 2020).

عينة الدراسـة:

اقتصرت عينة الدراسة على الطلاب الذين استجابوا للنموذج الثالث من كراسات الاختبار وعددهم 405

طالبا وطالبة.

أداة الدراسة:

يشكل الاختبار الدولي 2019 TIMSS لمادة العلوم للصف الثاني المتوسط مصدرًا للبيانات، وهو الذي

اعتمدت عليه هذه الدراسة.

إجراءات الحصول على البيانات وتحليلها:

تم الحصيول على البيانات وفق الخطوات الآتية:

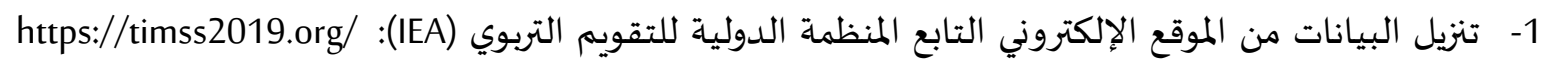

/international-database

2- اختيار ملف إجابات طلاب المملكة العربية السعودية على اختبار TIMSS في مادة العلوم التي تحمل رمز

.BSASAUM7

3- فرز البيانات حسب رقم النموذج وعلى فقرات مادة العلوم، حيث اختير النموذج الثالث من كراسات

الاختبار، وذلك لاحتوائه على أكبر عدد من فقرات الاختيار من متعدد والبالغ عددهات وعا (22) فقرة.

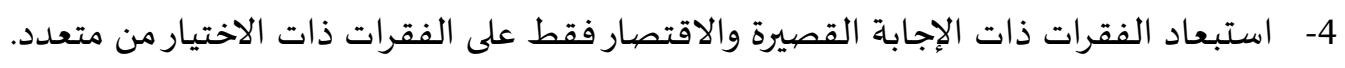

5- تصحيح النموذج من خلال ملف T19_G8_Item Information.

وقبل الإجابة عن أسئلة الدراسة تم التحقق أولًا من افتراضات نظرية الاستجابة للفقرة، إضافة إلى التحقق

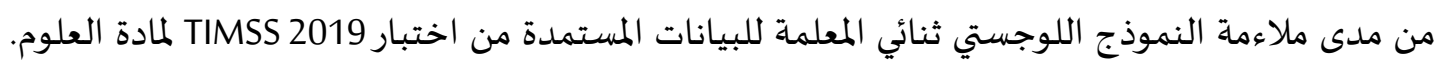

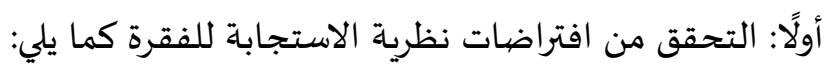




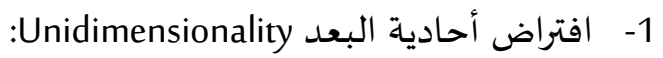

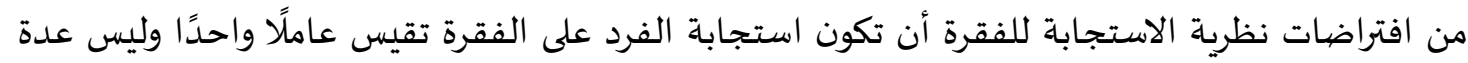

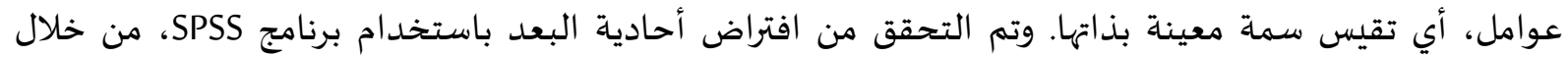
التحليل العاملي الاستكشافي (Factor Analysis) بطريقة المكونات الرئيسية (Frincipal Component) للنموذج الثالث

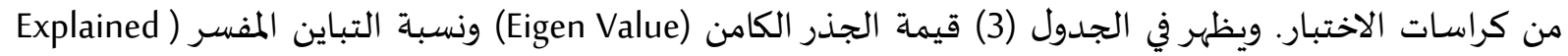
(Variance وكذلك التباين المفسر التراكمي لكل عامل من العوامل: جدول (3): قيم الجذور الكامنة ونسبة التباين المفسروالتراكمي لنموذج المبر الاختبار.

\begin{tabular}{|c|c|c|c|c|}
\hline الجذذر الكامن الأول & نسبة التباين المفسر التراكمي & نسبة التباين المفسر & الجذر الكامن & العامل \\
\hline \multirow[t]{8}{*}{2.38} & 15.89 & 15.89 & 3.50 & 1 \\
\hline & 22.55 & 6.66 & 1.47 & 2 \\
\hline & 28.37 & 5.81 & 1.28 & 3 \\
\hline & 33.98 & 5.61 & 1.24 & 4 \\
\hline & 39.04 & 5.06 & 1.11 & 5 \\
\hline & 43.99 & 4.96 & 1.10 & 6 \\
\hline & 48.85 & 4.85 & 1.07 & 7 \\
\hline & 53.47 & 4.62 & 1.02 & 8 \\
\hline
\end{tabular}

يتضح من الجدول رقم (3) أن العامل الأول يفسر أكبر نسبة تباين في درجات الأفراد مقارنة ببقية العوامل.

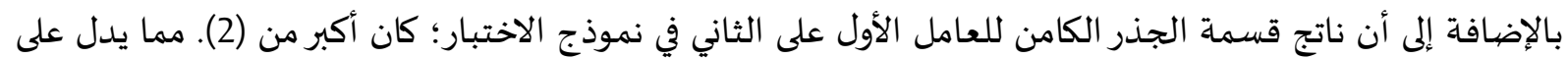
وجود سمة سائدة للاختبار، وبالتالي يمكن القول بتحقق افتراضية أحادية البعد للاختبار (Hattie, 1985).

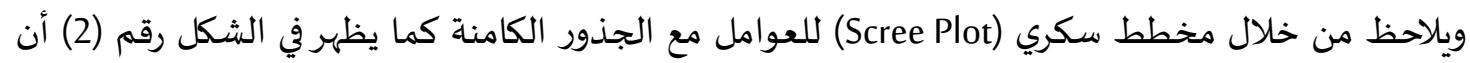

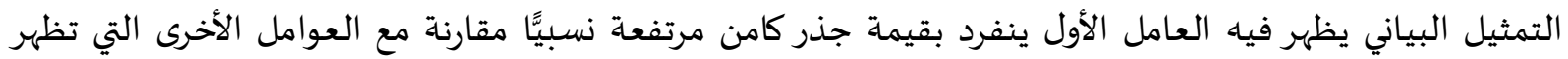

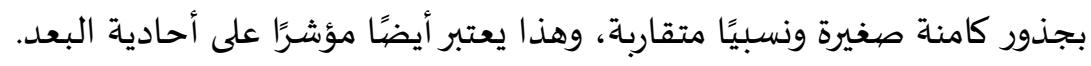




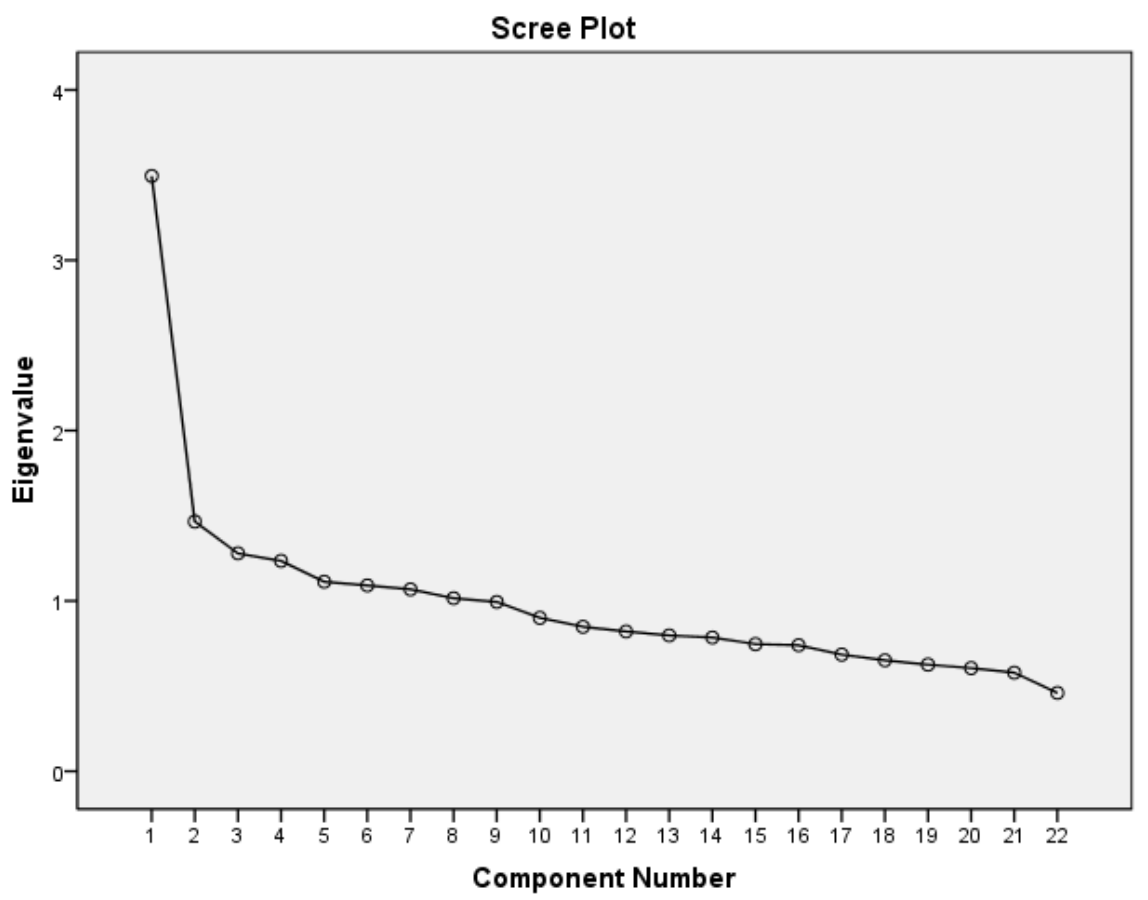

شكل (2): مخطط سكري لقيم الجذور الكامنة للعوامل في نموذج الاختبار.

2- افتراض الاستقلال الموضعي Local Independence:

يتضمن هذا الافتراض أن إجابة الطالب عن الفقرة لا تتأثر بإجابته عن فقرة أخرى والعامل الوحيد المؤثر

على احتمال الإجابة عن الفقرة هو مقدار القدرة () 0 وخصائص الفقرة. وهذا الافتراض مكافئ لافتراض أحادية

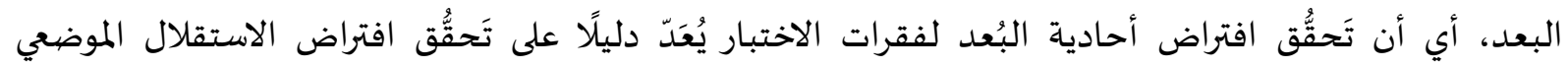

(Hambleton \& Swaminathan, 1985)

3- التحرر من السرعة في الأداء:

يمكن التأكد من أن الاختبار ليس اختبار سرعة من خلال فحص نسبة الطلاب الذين أكملوا الاختبار،

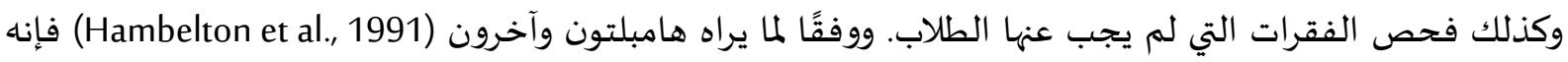

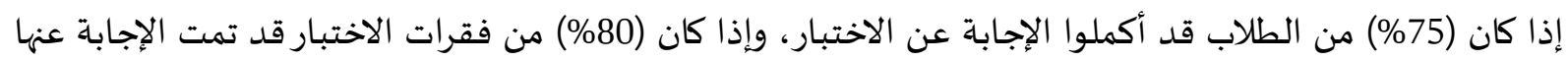

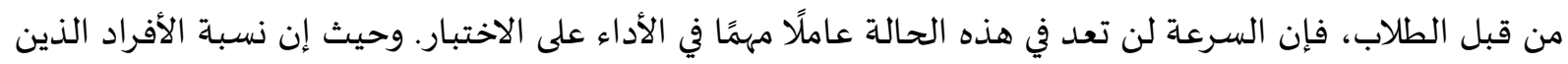

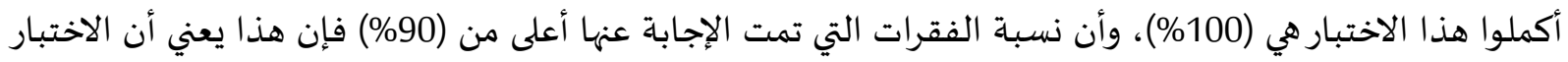
يقيس القوة وليس السرعة.

ثانيًا- مطابقة الأفراد والفقرات للنموذج اللوجستي الثنائي المعلمة: استخدم برنامج (Bilog-MG3)؛ للتأكد من مطابقة الأفراد (Person-Fit)، ومطابقة الفقرات (Item-Fit)

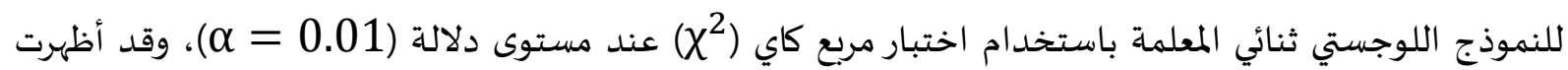

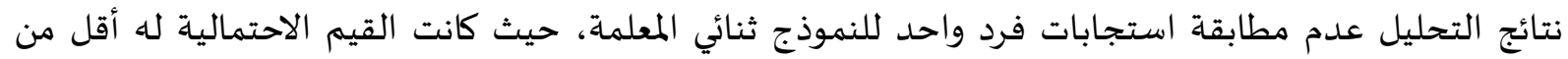
(0.01)؛ لذا تم حذف استجابته وأصبح حجم العينة في صورتها النهائية (404) أفراد. 
وفيما يتعلق بفحص مطابقة الفقرات للنموذج المستخدم أُعيد التحليل باستخدام برنامج (Bilog-MG3)

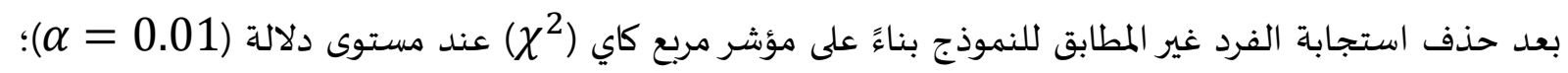
وكانت النتائج كما يلي:

جدول (4): مطابقة فقرات الاختبار للنموذج الثنائي المعلمة

\begin{tabular}{|c|c|c|c|c|c|}
\hline P-Value & قيمة & رقم الفقرة & P-Value & قيمة & رقم الذقرة \\
\hline 0.98 & 1.5 & 12 & 0.95 & 2.2 & 1 \\
\hline 0.33 & 9 & 13 & 0.86 & 3.3 & 2 \\
\hline 0.43 & 4.9 & 14 & 0.7 & 5.5 & 3 \\
\hline 0.48 & 5.5 & 15 & 0.08 & 14.2 & 4 \\
\hline 0.29 & 6.2 & 16 & 0.12 & 10 & 5 \\
\hline 0.02 & 14.9 & 17 & 0.80 & 4.6 & 6 \\
\hline 0.36 & 8.8 & 18 & 0.3 & 9.5 & 7 \\
\hline 0.06 & 11.9 & 19 & 0.83 & 3.5 & 8 \\
\hline 0.8 & 4.6 & 20 & 0.62 & 5.3 & 9 \\
\hline 0.48 & 7.5 & 21 & 0.25 & 10.2 & 10 \\
\hline 0.67 & 5.8 & 22 & 0.77 & 4.9 & 11 \\
\hline
\end{tabular}

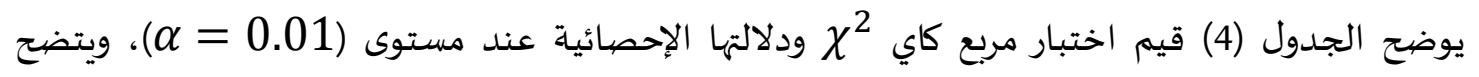
مطابقة جميع فقرات الاختبار للنموذج ثنائي المعلمة، حيث كانت القيمة الاحتمالية أكبر من (0.01) لجميع الفقرات. الأساليب الإحصائية:

من أجل الإجابة عن أسئلة الدراسـة تم استخدام البرامج الإحصيائية الآتية:

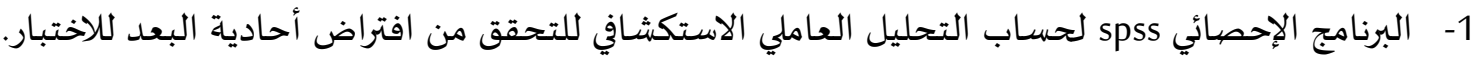

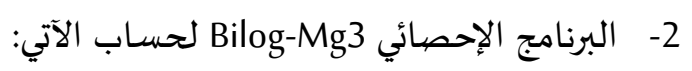
اختبار مريع كاي $\chi^{2}$ لحسن المطابقة للكشف عن مدى مطابقة الأفراد والفقرات للنموذج اللوجستي ثنائي المعلمة.

معامل صعوبة الفقرة والتمييزوفق النموذج ثنائي المعلمة. دقة تقدير معلمة صعوبة وتمييز الفقرة والقدرة وفق النموذج ثنائي المعلمـة. ثبات الاختبار الإمبريقي.

4- 4 - نتائج الدراسـة ومناقشتها.

النتائج المتعلقة بالإجابة عن السؤال الأول: ما دقة تقدير معلمة الصعوبة لفقرات اختبار 2019 TIMSS

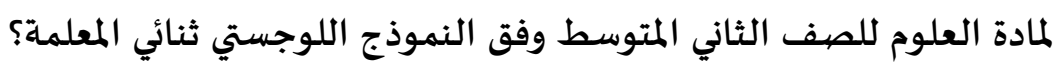

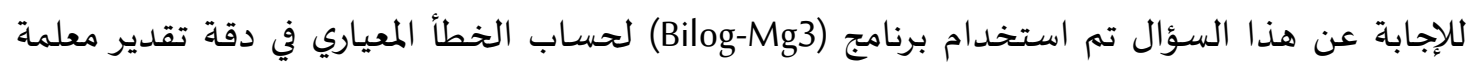
الصعوبة لفقرات الاختبار TIMSS 2019 كما هو موضَّح في الجدول (5)، والذي يوضِّح كذلك تقديرات معلمة 
الصعوبة وحساب المتوسط الحسابي والانحراف المعياري لمعلمة الصعوبة والخطأ المعياري لدقة تقدير معلمة

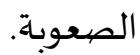

جدول (5): تقديرات قيم معلمة الصعوبة والأخطاء المعيارية في تقدير معلمة الصعوبة.

\begin{tabular}{|c|c|c|c|c|c|}
\hline الخطأ المعياري & معلمة الصيعوبة & رقم الفقرة & الخطأ المعياري & معلمة الصعوبة & رقم الفقرة \\
\hline 1.08 & 4.04 & 12 & 0.39 & -1.79 & 1 \\
\hline 0.4 & 1.51 & 13 & 0.15 & 0.81 & 2 \\
\hline 0.15 & -1.19 & 14 & 0.29 & 0.54 & 3 \\
\hline 0.098 & -0.69 & 15 & 0.457 & 2 & 4 \\
\hline 0.11 & -0.72 & 16 & 0.218 & -1.35 & 5 \\
\hline 0.11 & -0.67 & 17 & 0.41 & 1.71 & 6 \\
\hline 0.19 & 0.86 & 18 & 0.298 & 0.90 & 7 \\
\hline 0.11 & -0.59 & 19 & 0.115 & 0.25 & 8 \\
\hline 0.14 & 0.07 & 20 & 0.133 & -0.17 & 9 \\
\hline 0.16 & 0.59 & 21 & 0.186 & 0.71 & 10 \\
\hline 0.13 & 0.11 & 22 & 0.485 & 2.27 & 11 \\
\hline 0.22 & 1.36 & الانحراف الكلي & 0.26 & 0.42 & المتوسط الكلي \\
\hline
\end{tabular}

يتضح من الجدول (5) أن فقرات الاختبار تتّسم بدرجات متفاوتة من السهولة والصعوبة، حيث تراوحت

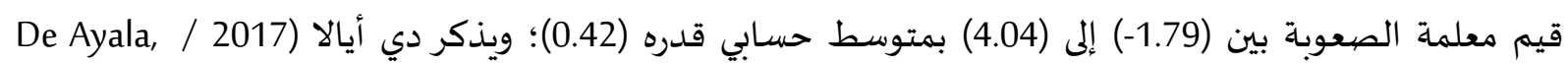

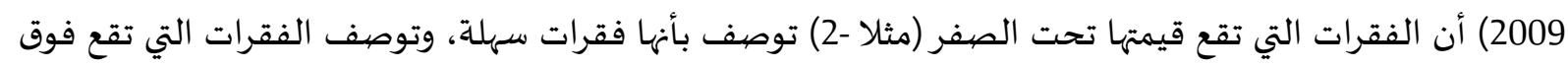
الصفر بأنها فقرات صعبة (مثلًا +2) ، أما الفقرات الواقعة نحتَ نحو الصفر فتُعتبر فقرات متوسطة الصعوبة. وبناءً على ما

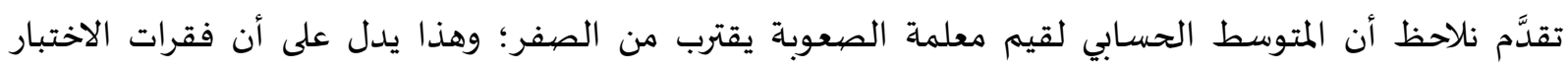

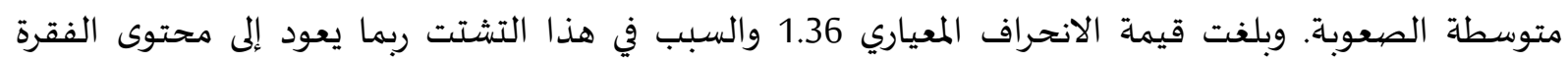

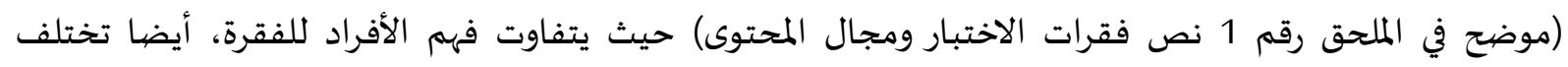

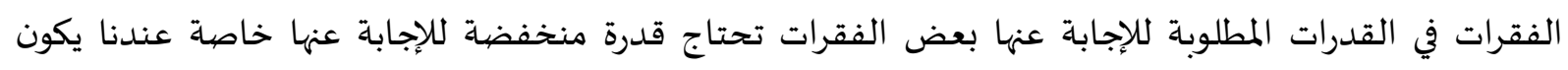

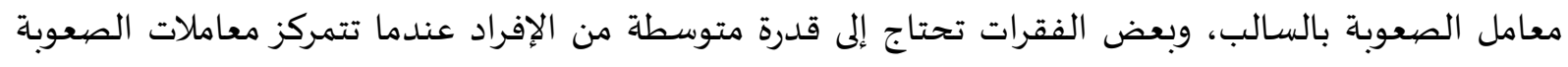

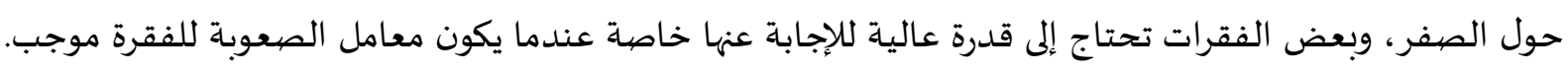

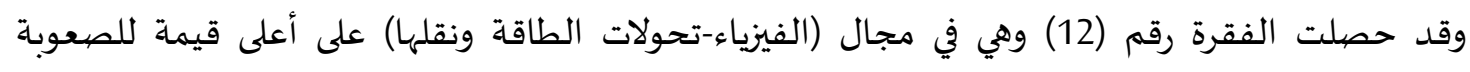

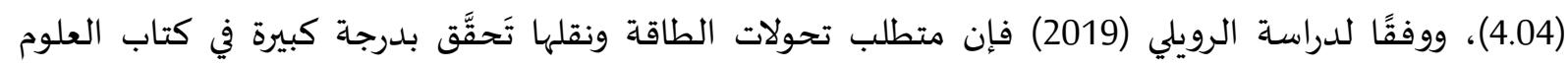

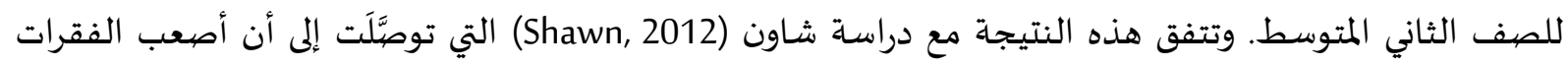
هي التي تُقيم مستوى الاستدلال والتطبيق. في حين حصلت الفقرة رقم (1) وهي في في مجال (الكيمياء-التغير الكيميائي)

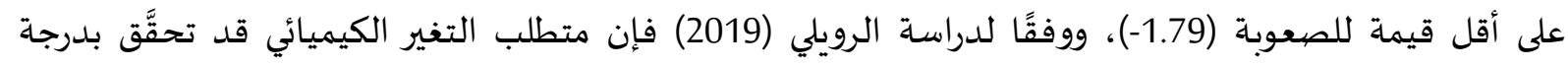

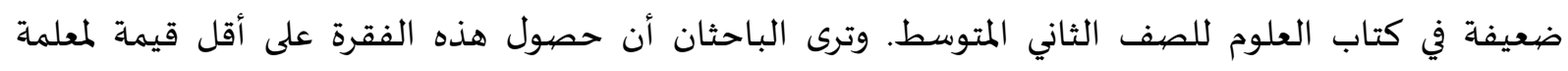

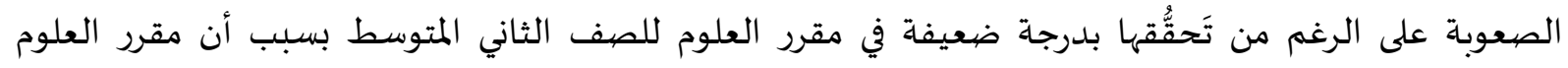


للصف الأول المتوسط يحوي وحدة (طبيعية المادة) التي تتضمَّن فصل (المادة وتغيُّراتها). أيضا تتفق هذه النتيجة مع

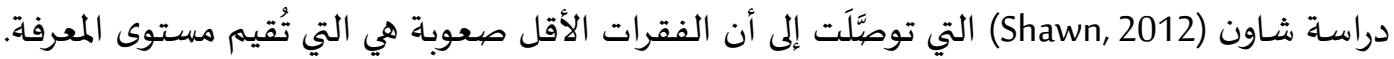

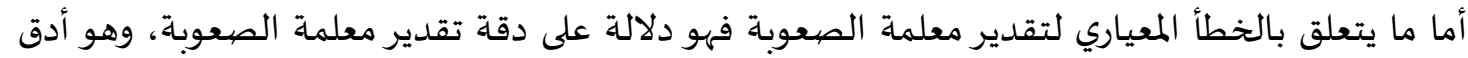

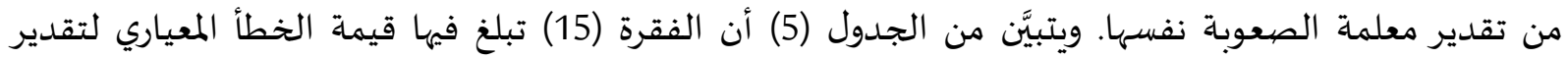

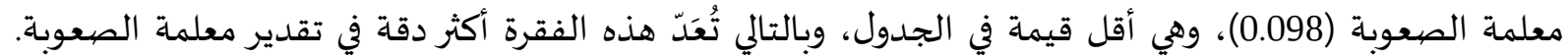
وهي في مجال (علم الأرض- استخدام موارد الأرض وحفظها)، وقد تحقَّق هذا المطلب بدرجة كبيرة في مقرر العلوم

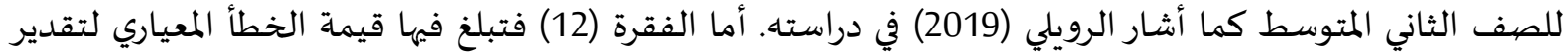

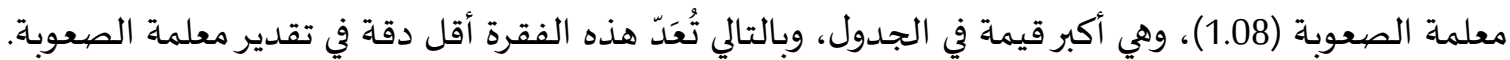

النتائج المتعلقة بالإجابة عن السؤال الثاني: ما دقة تقدير معلمة التمييز لفقرات اختبار 2019 TIMSS لمادة

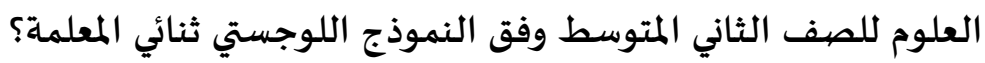

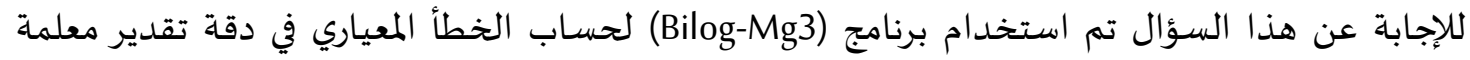
التمييز لفقرات الاختبار TIMSS 2019 كما هو موضَّح في الجدول (6) والذي يوضح كذلك تقدئ تقديرات معلمة التمييز وحساب المتوسط الحسابي والانحراف المعياري لدقة تقدير معلمة التمييز. جدول (6): تقديرات قيم معلمة التمييزوالأخطاء المعيارية في تقدير معلمة التمييز.

\begin{tabular}{|c|c|c|c|c|c|}
\hline الخطأ المعياري & معلمة التمييز & رقم الفقرة & الخطأ المعياري & معلمة التمييز & رقم الفقرة \\
\hline 0.1 & 0.39 & 12 & 0.14 & 0.61 & 1 \\
\hline 0.1 & 0.46 & 13 & 0.16 & 1.06 & 2 \\
\hline 0.25 & 1.43 & 14 & 0.09 & 0.38 & 3 \\
\hline 0.24 & 1.5 & 15 & 0.11 & 0.51 & 4 \\
\hline 0.23 & 1.36 & 16 & 0.18 & 0.95 & 5 \\
\hline 0.21 & 1.39 & 17 & 0.11 & 0.49 & 6 \\
\hline 0.13 & 0.77 & 18 & 0.1 & 0.45 & 7 \\
\hline 0.18 & 1.26 & 19 & 0.16 & 1.07 & 8 \\
\hline 0.14 & 0.77 & 20 & 0.15 & 0.82 & 9 \\
\hline 0.13 & 0.79 & 21 & 0.13 & 0.73 & 10 \\
\hline 0.14 & 0.88 & 22 & 0.12 & 0.55 & 11 \\
\hline 0.05 & 0.36 & الانحراف الكلي & 0.15 & 0.85 & المتوسط الكلي \\
\hline
\end{tabular}

يتّضح من الجدول (6) أن قيم معلمة التمييز تراوحت بين (0.38) إلى (1.50) بمتوسط حسابي قدره (0.85)؛

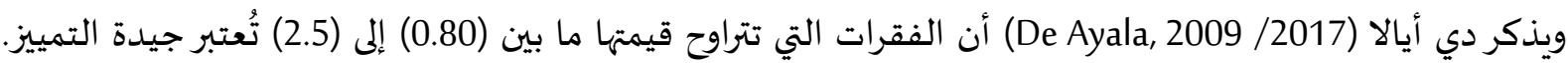

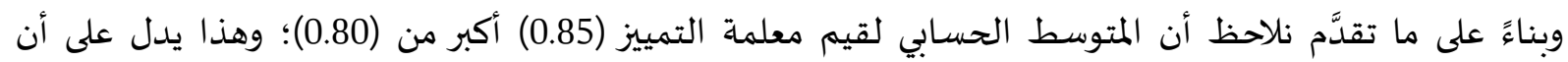
فقرات الاختبار جيدة التمييز. أما ما يتعلق بالخطأ المعياري لتقدير معلمة التمييز فيتضح من الجدارول (6) أن الفقرة (3) تبلغ فيها قيمة

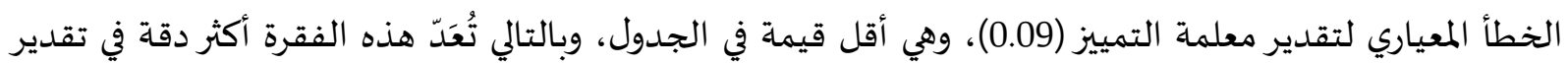


معلمة التمييز. وهي في مجال (الفيزياء-الضوء والصوت)، وقد تَحقَّق هذا المطلب بدرجة كبيرة في مقرر العلوم للصف

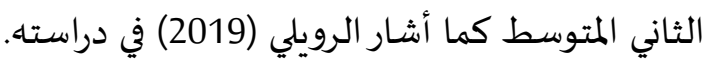

النتائج المتعلقة بالإجابة عن السؤال الثالث: ما دقة تقدير القدرة لأداء الطلاب المشاركين على اختبار

TIMSS 2019

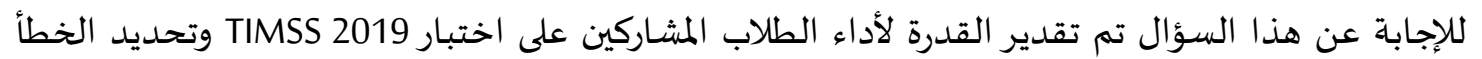

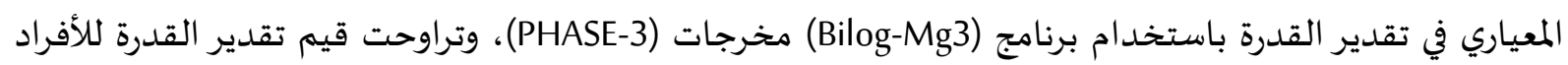

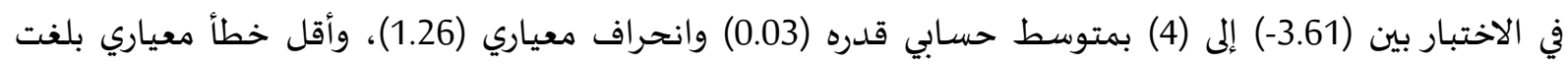

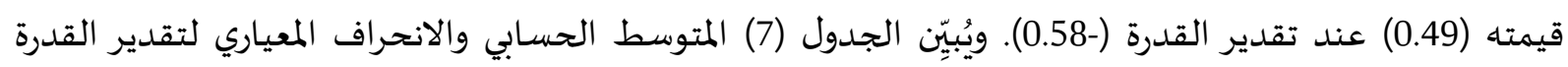
والخطأ المعياري في تقديرها.

جدول (7): قيم المتوسط الحسابي والانحراف المعياري لتقدير قدرة الأفراد والخطأ المعياري في تقدير القدرة.

\begin{tabular}{|c|c|c|}
\hline الخطأ المعياري & تقدير القدرة & المتوسط/ الانحراف \\
\hline 0.49 & 0.03 & المتوسط الحسابي \\
\hline 0.13 & 1.26 & الانحراف المعياري \\
\hline
\end{tabular}

وذكر دبوس (2016) في دراسته أنه إذا كان متوسط تقديرات القدرة للأفراد أكبر من متوسط تقديرات

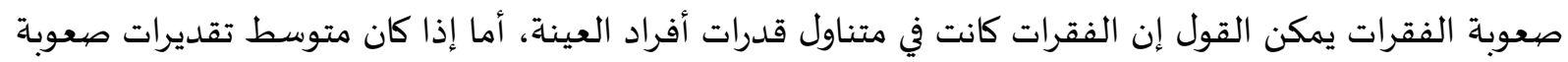

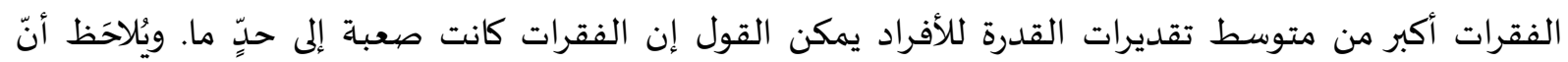

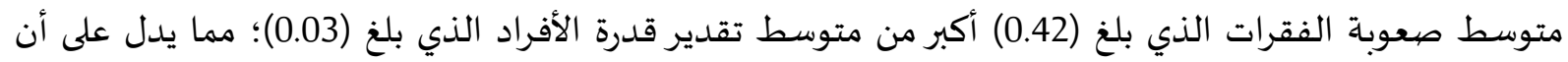

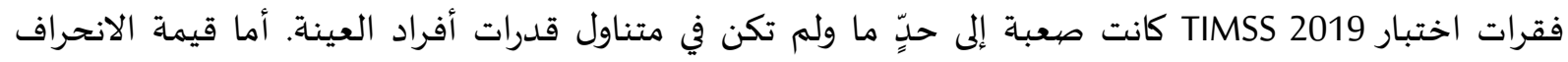

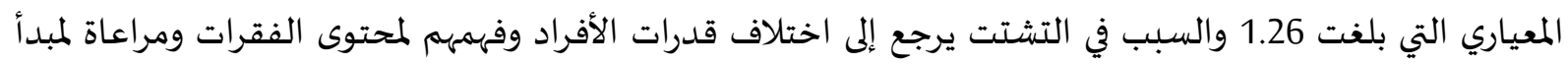
الفروق الفردية بين المفحوصين.

وتم حساب تكرارات الأفراد حسب درجات الاختبار، ومتوسط تقدير القدرة، ومتوسط الخطأ المعياري

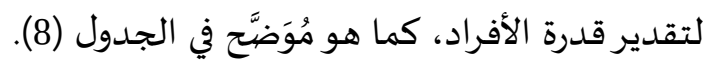

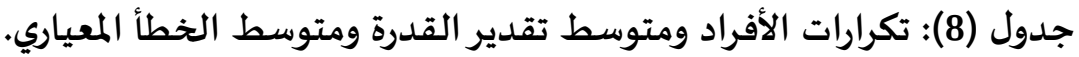

\begin{tabular}{|c|c|c|c|}
\hline متوسط الخطأ المعياري & متوسط تقدير القدرة & التكرارات & الدرجة \\
\hline 1.26 & -3.61 & 1 & 1 \\
\hline 0.98 & -3.01 & 4 & 2 \\
\hline 0.67 & -2.03 & 5 & 3 \\
\hline 0.6 & -1.74 & 15 & 4 \\
\hline 0.56 & -1.47 & 22 & 5 \\
\hline 0.54 & -1.28 & 21 & 6 \\
\hline 0.51 & -.95 & 30 & 7 \\
\hline 0.5 & -.63 & 40 & 8 \\
\hline 0.5 & -.41 & 35 & 9 \\
\hline 0.51 & -.13 & 39 & 10 \\
\hline
\end{tabular}




\begin{tabular}{|c|c|c|c|}
\hline متوسط الخطأ المعياري & متوسط تقدير القدرة & التكرارات & الدرجة \\
\hline 0.53 & 0.12 & 36 & 11 \\
\hline 0.54 & 0.28 & 31 & 12 \\
\hline 0.58 & 0.69 & 28 & 13 \\
\hline 0.62 & 0.97 & 24 & 14 \\
\hline 0.66 & 1.27 & 29 & 15 \\
\hline 0.73 & 1.67 & 19 & 16 \\
\hline 0.84 & 2.21 & 7 & 17 \\
\hline 0.97 & 2.77 & 8 & 18 \\
\hline 1.11 & 3.27 & 6 & 19 \\
\hline 1.27 & 3.96 & 4 & 20 \\
\hline
\end{tabular}

يتضح من الجدول (8) أن مدى الدرجات يمتدّ من (1) إلى (20) درجة، ويُلاحَظ أن الطالب الذي قدرته (-

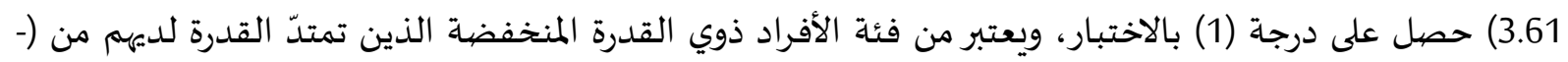

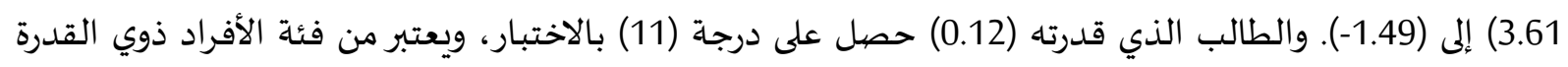

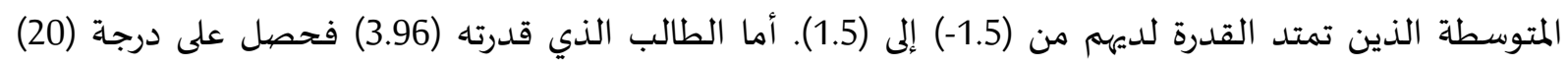
بالاختبار، ويُعتبر من فئة الأفراد ذوي القدرة المرتفعة الذين تمتد القدرة لديهم من (1.51) (1.51، 4).

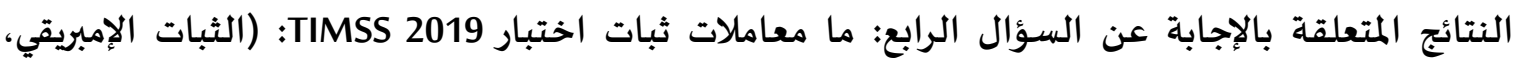

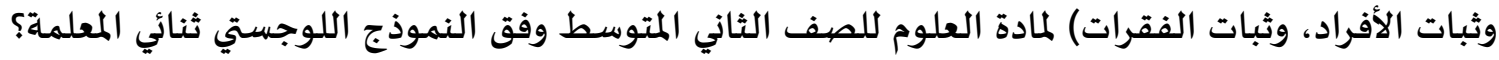

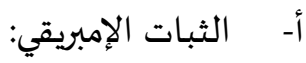

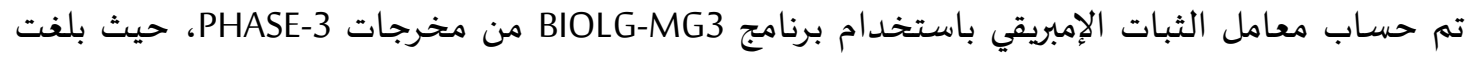
قيمة معامل الثبات الإمبريقي (0.78)، وهي قيمة مقبولة وتُعَدِّ مؤشرًا جيدًا للاختبار.

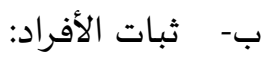

بلغت قيمة المتوسط الحسابي لتقدير قدرات الأفراد (0.0324) بانحراف معياري (1.256)، كما بلغت قيمة

المتوسط الحسابي للخطأ المعياري في تقدير القدرة (0.5873) بانحراف معياري (0.1336).

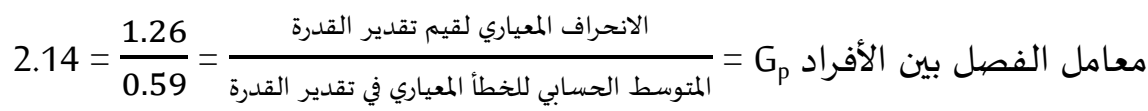

$$
\begin{aligned}
& \text { معامل الثبات للأفراد:R } \\
& R_{p}=\frac{G^{2}}{1+G^{2}}=0.82
\end{aligned}
$$

ونلاحظ أن معامل الفصل بين الأفراد بلغت قيمته (2.14)، وهي أكبر من (2)؛ مما يدل على أن عينة الأفراد

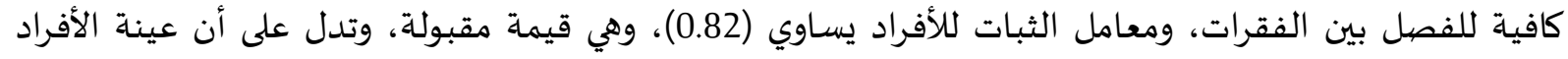
كانت كافية للفصل بين الفقرات. 
بلغت قيمة المتوسط الحسابي لتقدير صعوبة الفقرات (0.42) بانحراف معياري (1.36)، كما بلغت قيمة المتوسط الحسابي للخطأ المعياري في تقدير القدرة (0.26) بانحراف معياري (0.22).

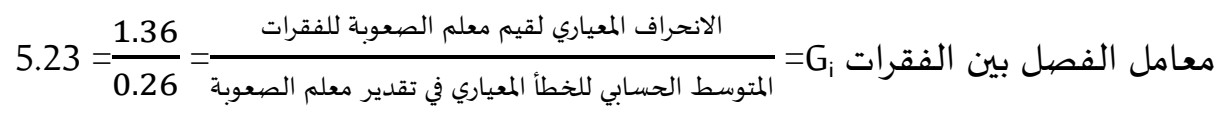
معامل الثبات للفقرات R

$$
R_{i}=\frac{G^{2}}{1+G^{2}}=0.96
$$

ونلاحظ أن معامل الفصل بين الفقرات بلغت قيمته (23 .5) وهي أكبر من (2)؛ مما يدل على أن عينة

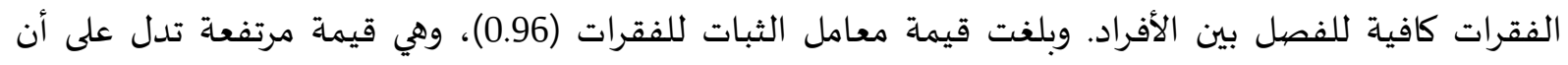
فقرات الاختبار كانت كافية للتمييز بين قدرات الأفراد.

مناقشـة النتائج:

هدفت هذه الدراسة إلى الكشف عن دقة تقدير معلمة الصعوبة والتمييز للفقرة والقدرة لاختبار TIMSS

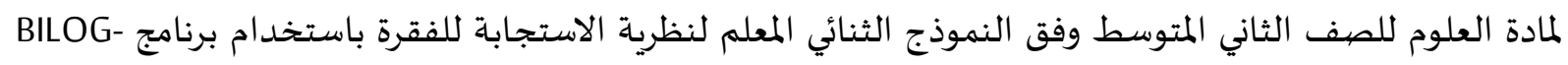

.MG3

مناقشة النتائج المتعلقة بالسؤال الأول حيث أظهرت النتائج إن الفقرات تتمتع بمؤشرات متوسطة

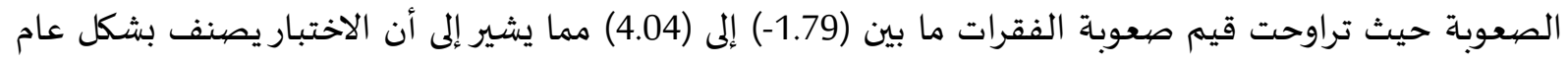

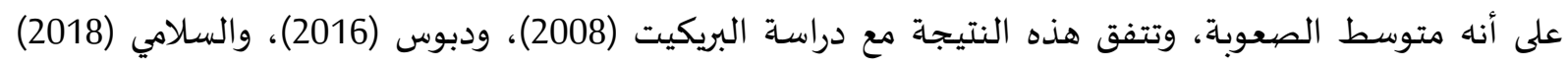

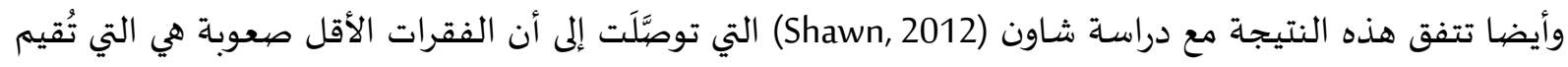

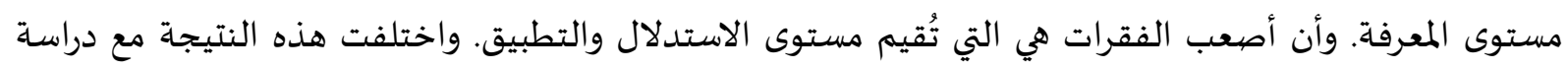

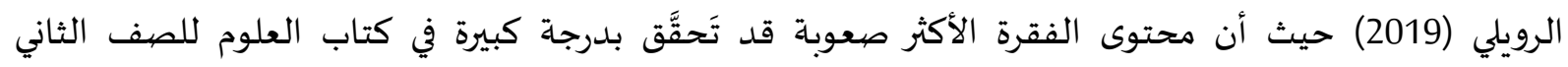

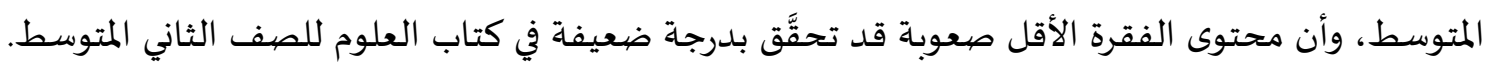

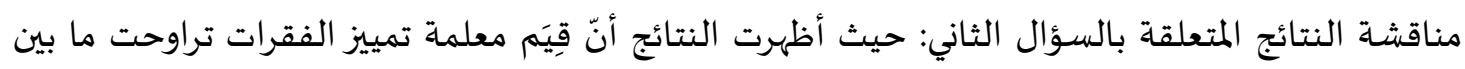

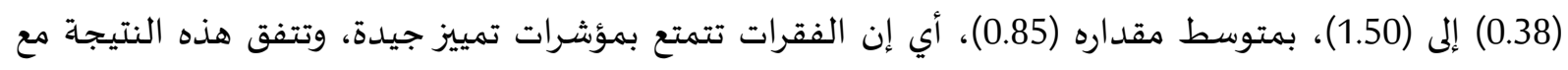

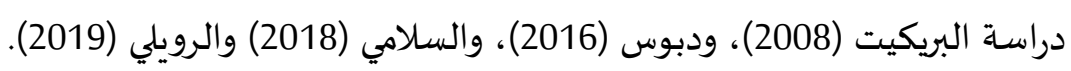

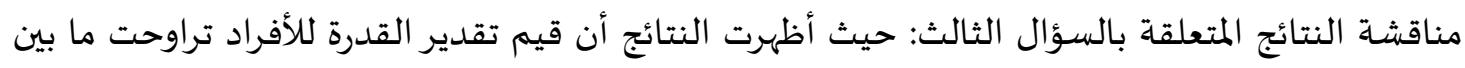

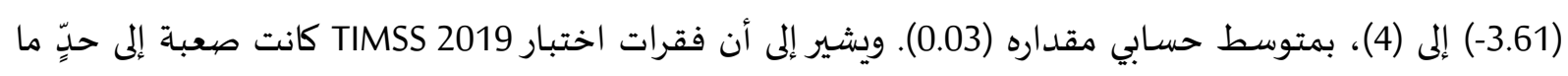

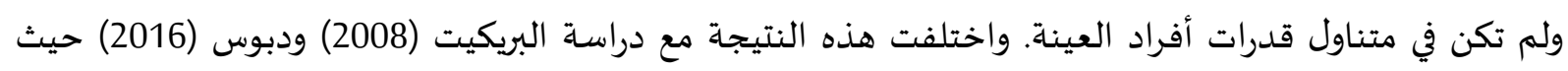

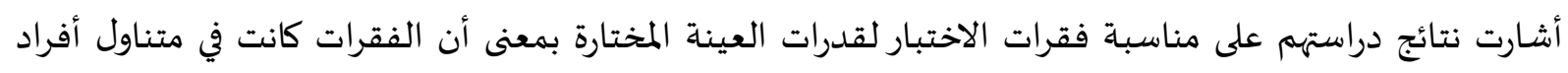
العينة.

مناقشَة النتائج المتعلقة بالسؤال الرابع: أظهرت النتائج أنّ قيمة معامل الثبات الإمبريقي تساوي (0.78)، أما

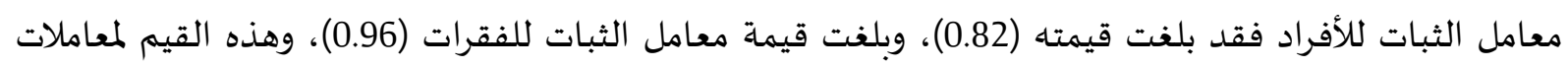

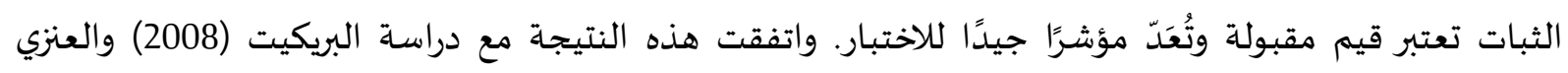

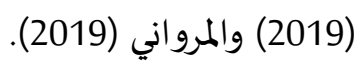


بناءً على ما أسفرت عنه نتائج الدراسـة، يوصي الباحثان ويقترحان ما يلي:

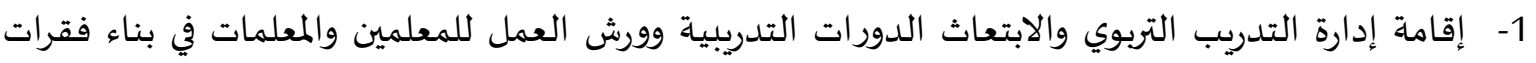

الاختبارات وفق مستويات اختبار TIMSS.

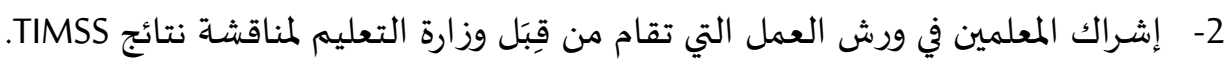

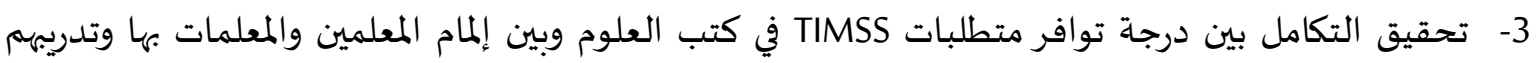
عليها، وتحسين مهاراتهم وقدرتهم على تنميتها لدى الطلاب.

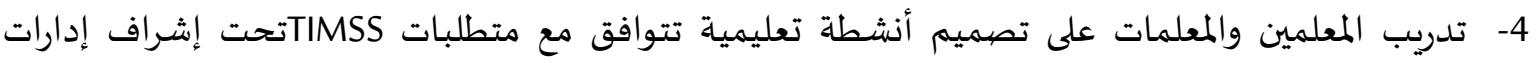
التدريب التربوي. 5- استخدام إدارة الاختبارات والقبول نماذج الاستجابة للفقرة في بناء أدوات واختبارات جديدة والتحقق من الخصائص السيكومترية لها. 6- كما تقترح الباحثان ما يلي: 1. تحليل بيانات الدراسة وفق النموذج الأحادي والثلاثي ومقارنها بنتائج هذه الدراسة. 2. دراسة تقدير معالم الفقرة والقدرة للأفراد المشاركين في اختبار TIMSS لمادة الرياضيات وفق وفئنسات نظرية الاستجابة للفقرة. 3. دراسة مقارنة لتقدير معالم الفقرة والقدرة للأفراد المشاركين في اختبار TIMSS بين المملكة العربية السعودية

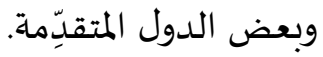
4. دراسة بناء اختبار محكي يقيس المهارات العلمية لمادة العلوم للمرحلة المتوسطة.

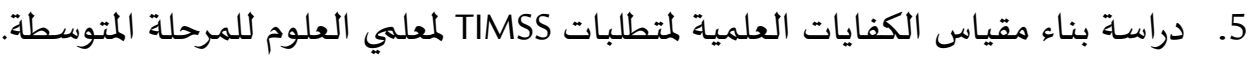
6. إجراء المزيد من الأبحاث عن اختبار TIMSS باستخدام النماذج الأخرى لنظرية الاستجابة للفقرة.

- أبو عواد، فريال محمد عثمان. (2018). استقصاء تقديرات معالم الفقرات والقدرة ودالة المعلومات لاختبار

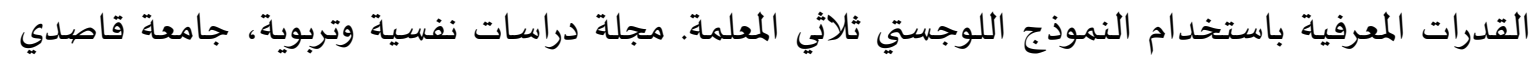

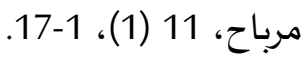
- البريكيت، ممدوح سليمان. (2008). استخدام نموذج راش في انتقاء بنود اختبار تيمس (TIMSS) للمهارات الرياضية لطلاب الصف الثاني المتوسط [رسالة ماجستير غير منشورة]. جامعة الملك سعود. الجراح، بندر نواف. (2020). الكشف عن أنماط الاستجابة في اختباري العلوم والرياضيات الدوليين لبيانات لدى عينة من طلبة الدولة السعودية ودولة سنغافورة باستخدام مؤشرات مطابقة الشخص. مجلة العلوم التربوية: جامعة الملك سعود - كلية التربية، 32(2)، 299-320.

- - حسان، محمود عبد اللطيف محمود. (2013). تقويم محتوى المناهج في ضوء المتطلبات المعرفية لمشروع التيمز

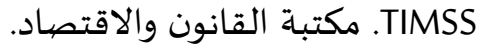


- دبوس، محمد طالب. (2016). استخدام نظرية الاستجابة للفقرة في بناء فقرات اختبار محكي المرجع في الرياضيات بفقرات ثنائية التدريج ومتعددة التدريج وفق النموذج اللوجستي ثنائي المعلم. مجلة جامعاة النجاح الوطنية، 30 (7)، 1453-1480.

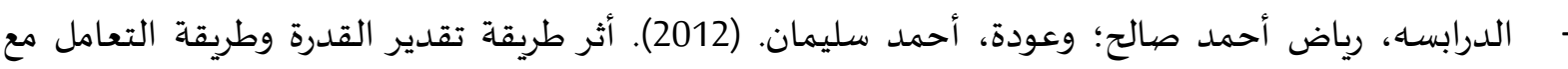

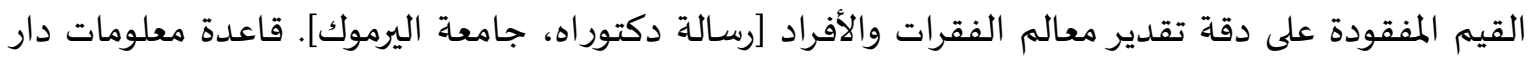

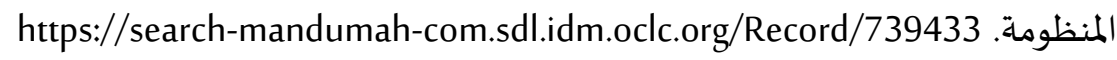
دي إيالا، ر.ج (2017). النظرية والتطبيق في نظرية الاستجابة للفقرة. (عبد الله الكيلاني وإسماعيل البرصان، ترجمة). دار جامعة الملك سعود للنشر. (العمل الأصلي نشر في 2009). 2001). الرويلي، فارس. (2019). تحليل محتوى مقرر العلوم للصف الثاني المتوسط في المملكة العربية السعودية في ضوء متطلبات دراسة التوجهات الدولية للرياضيات والعلوم 2015 TIMSS [ماجستير غير منشورة]. جامعة فئس الجوف. السلامي، عبد الله محمد. (2018). بناء اختبار محكي المرجع في الرياضيات باستخدام نظرية الاستجابة للمفردة

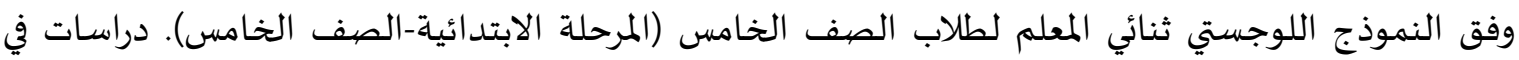

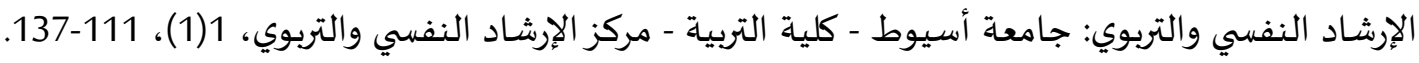

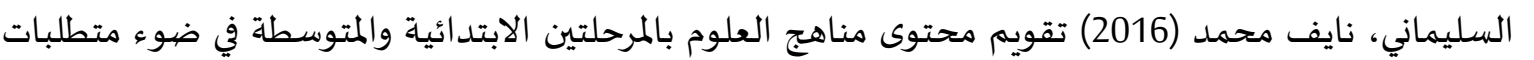
دراسة التوجهات الدولية السادسة للرياضيات والعلوم (TIMSS) [رسالة دكتوراه غير منشورة]. جامعة الملك منكايك

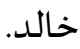

الشمراني، صالح؛ الشمراني، سعيد؛ البرصان، اسماعيل؛ والدوراني، بكيل. (2016). اضاءات حول نتائج دول

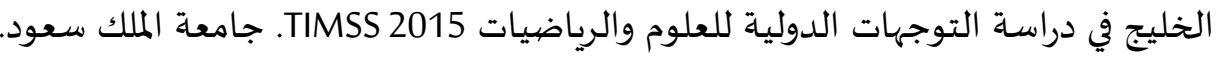
الشيخي، هاشم سعيد. (2012). إستراتيجية مقترحة لتحسين مستوى تحصيل طلبة المملكة العربية السعودية في الرياضيات في المسابقة الدولية (TIMSS). الجامعاة الأردنية- عمادة البحث العلمي، 39 (1)، 33-60. عباس، محمد؛ نوفل، محمد؛ العبسي، محمد؛ وأبو عواد، فريال. (2007). مدخل إلى مناهج البحث في التربية

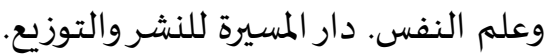

علام، صلاح الدين محمود. (2005). نماذج الاستجابة للمفردة الاختبارية أحادية البعد ومتعددة الأبعاد وتطبيقاتها في القياس النفسي والتربوي. دار الفكر العربي. علام، صلاح الدين محمود. (2011). القياس والتقويم التربوي والنفسي: أساسياته وتطبيقاته وتوجهاته المعاصرة

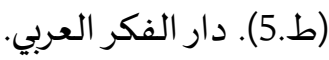
- العنزي، محمد عويض؛ وعبد العال، صبري محمد. (2019). أثر شكل فقرة الاختيار من متعدد والصيواب والخطأ

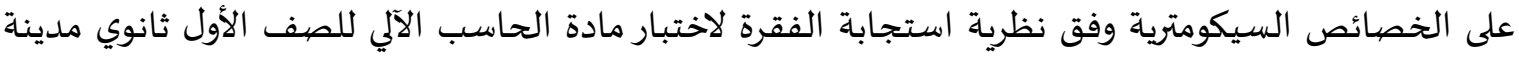

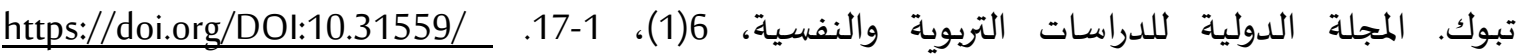
EPS2019.6.1.1 - عودة، أحمد سليمان. (2010). القياس والتقويم في العملية التدريسية (ط.4). دار الأمل. 
- الفهيدي، هذال عبيد. (1433هـ). تقويم محتوى مقررات العلوم المطورة بالمرحلة الابتدائية في المملكة العربية

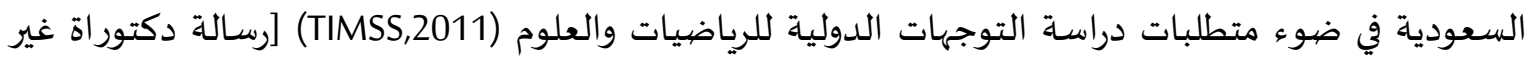
منشورة] جامعة أم القرى. كروكر، ليندا ؛ وألجينا، جيمس (2017). مدخل إلى نظرية القياس التقليدية والمعاصرة. (هند الحموري وزينات

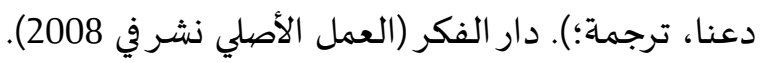
المرواني، أشواق ضيف الله؛ وسليمان، شاهر خالد. (2019). أثر موقع البديل الصحيح في اختبار اختيار من

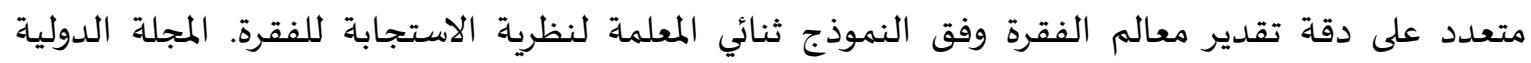

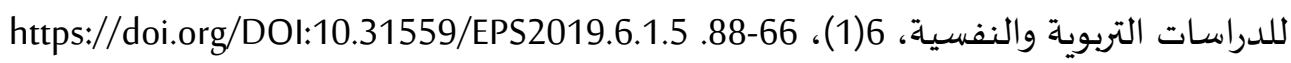
هيئة تقويم التعليم والتدريب ETEC. (1439). نبذة حول الاختبارات الدولية DIMSS PIRLS PISA TALIS. https://www.etec.gov.sa/ar/Media/Publications/\%d8\%a7\%d9\%84\%d9\%86\%d8\%b4\%d8\%b1\%d8\% a7\%d8\%aa\%201439 - - هيئة تقويم التعليم والتدريب ETEC. (2020). تقرير تيمز 2019 نظرة أولية في تحصيل طلبة الصفين الرابع

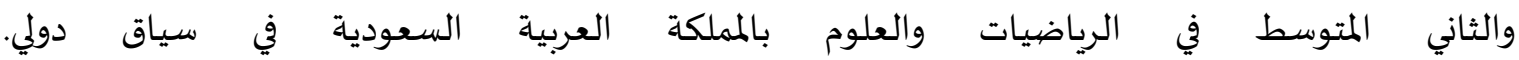
https://www.etec.gov.sa/ar/Researchers/Research-Studies/Documents/TIMSS\%202019.pdf هيئة تقويم التعليم والتدريب ETEC. (د.ت.) الدليل الارشادي للاختبارات الدولية 2019 TIMSS. https://www.etec.gov.sa/ar/productsandservices/Qiyas/internationaltests/TIMSS/Documents/TIMS S_International_Testing_Guides.pdf https://edu.moe.gov.sa/Mokhwah/ مادتي العلوم والرياضيات TIMSS وزارة التعليم. (د.ت.) دليل اختبارات Departments/mdir/jodh/Documents

ثانياً- المراجع بالإنجليزية:

- Baker, Frank b. (2001). The Basics of Item Response Theory. (2nd.ed). ERIC Clearinghouse on Assessment and Evaluation.

- Hambleton, R., \& Swaminathan, H. (1985). Item Response Theory: Principles and Applications. Kluwer Nijh off Publishing.

- Hattie, I (1985). Methodology Review: Assessing Unidimensionality of Tests and Items. Psychological Measurement, 9(2), 139-164.

- Mullis, Ina. Martin, Michael. (2017). TIMSS 2019 assessment frameworks. Boston College, TIMSS\& PIRLS international study center.

- Mullis, Ina. Martin, Michael. Foy, Pierre. Kelly, Dana and Fishbein, Bethany. (2020). TIMSS 2019 International Results in Mathematics and Science. Boston College, TIMSS\& PIRLS international study center.

- Shawn M. Glynn. (2012). International Assessment: A Rasch Model and Teachers' Evaluation of TIMSS Science Achievement Items. Journal of Research in Science Teaching, 49(10), 1321-1344. 
- Von Davier, M., Gonzalez, E., \& Schulz, W. (2020). Ensuring validity in international comparisons using state-of-the-art psychometric methodologies. In H. Wagemaker (Ed.), Reliability and validity of international large-scale assessments (pp. 187-219).

\begin{tabular}{|c|c|c|}
\hline 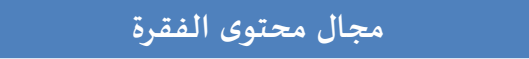 & 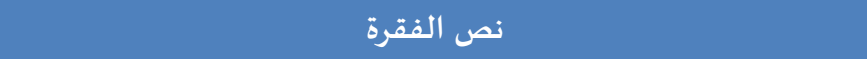 & 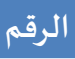 \\
\hline تغير كيميائي & عملية امتصاص الطاقة الضيوئية & 1 \\
\hline 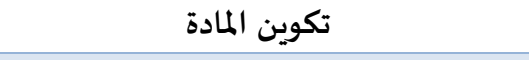 & نماذج ثاني أكسيد الكربون & 2 \\
\hline الضيوء والصيوت & صوت تستعمله الحيوانات & 3 \\
\hline تحويل الطاقة ونقلها & تسخين الماء على الموقد & 4 \\
\hline ت الطويل اقة ونقلها & تغيير الطاقة في الانزلاق & 5 \\
\hline هيكل الأرض والميزات الفيزيائية & مصدر المياه لتحلية المياه & 6 \\
\hline عمليات الأرض ودوراتها وتاريخها & سلسلة جبال على حافة المحيط & 7 \\
\hline الخصيائص والعمليات الحياتية للكائنات & خصائص غير عادية من النضناض & 8 \\
\hline الخلايا ووظائفها & أصل خلايا جديدة مع نمو الكائنات الحية & 9 \\
\hline 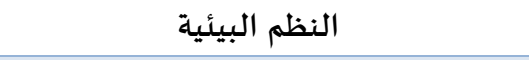 & تحديد الحيوانات المفترسة في الرسم التخطيطي & 10 \\
\hline النظم البيئية البية & كيف يدخل الكربون في الخشب & 11 \\
\hline ت الطويل اقة ونقلها & نقل الطاقة أثناء تغير درجة الحرارة & 12 \\
\hline الضوء والصهوت & أين يجب أن تقف ميغان & 13 \\
\hline موارد الأرض واستخدامها والمحافظة عليها & تقليل أو إعادة تدوير - العناصر التي تحتوي على القليل من التعبئة & 14 \\
\hline موارد الأرض واستخدامها والمحافظة عليها & إعادة التدوير - إعادة تعبئة زجاجات المياه البلاستيكية & 15 \\
\hline موارد الأرض واستخدامها والمححافظة عليها & تقليل البطاريات أو إعادة تدويرها - إعادة شحن البطاريات & 16 \\
\hline موارد الأرض واستخدامها والمحافظة عليها & قم بتقليل أو إعادة تدوير - كرتون جديد من الصناديق القديمة & 17 \\
\hline موارد الأرض واستخدامها والمحافظة عليها & التقليل أو إعادة التدوير - التسميد & 18 \\
\hline موارد الأرض واستخدامها والمحافظة علهيا & التقليل أو إعادة التدوير - باستخدام ألواح الطاقة الشمسية & 19 \\
\hline موارد الأرض واستخدامها والمحافظة عليها & تقليل أو إعادة تدوير - النوافذ من الزجاجات & 20 \\
\hline موارد الأرض واستخدامها والمحافظة عليها & لماذا تتعرض المنطقة للفيضانات في كثير من الأحيان بعد إزالة الغابات & 21 \\
\hline الأرض في النظام الشمسي والكون & كيف تنتج الشمس الضوء & 22 \\
\hline
\end{tabular}

